\title{
Oral probiotic activities and biosafety of Lactobacillus gasseri HHuMIN D
}

\author{
Soyon Mann ${ }^{1}$, Myeong Soo Park ${ }^{2}$, Tony V. Johnston ${ }^{3}$, Geun Eog ji ${ }^{2}$, Keum Taek Hwang ${ }^{1 *}$ and Seockmo Ku ${ }^{3^{*}}$ (D)
}

\begin{abstract}
Background: Lactobacillus spp. have been researched worldwide and are used in probiotics, but due to difficulties with laboratory cultivation of and experimentation on oral microorganisms, there are few reports of Lactobacillus spp. being isolated from the oral cavity and tested against oral pathogens. This research sought to isolate and determine the safety and inhibitory capabilities of a Lactobacillus culture taken from the human body.

Results: One organism was isolated, named "L. gasseri HHuMIN D", and evaluated for safety. A 5\% dilution of L. gasseri HHUMIN D culture supernatant exhibited 88.8\% inhibition against halitosis-producing anaerobic microorganisms and the organism itself exhibited powerful inhibitory effects on the growth of 11 oral bacteria. Hydrogen peroxide production reached $802 \mu \mathrm{mol} / \mathrm{L}$ after $12 \mathrm{~h}$ and gradually diminished until $24 \mathrm{~h}$, it efficiently aggregated with P. catoniae and S. sanguinis, and it completely suppressed S. mutans-manufactured artificial dental plaque. L. gasseri HHuMIN D's KB cell adhesion capacity was 4.41 cells per cell, and the cell adhesion of F. nucleatum and S. mutans diminished strongly in protection and displacement assays.
\end{abstract}

Conclusion: These results suggest that L. gasseri HHuMIN D is a safe, bioactive, lactobacterial food ingredient, starter culture, and/or probiotic microorganism for human oral health.

Keywords: Antimicrobial Effect, Lactobacillus gasseri, Oral Microorganisms, Biosafety Evaluation

\section{Introduction}

Oral diseases are acute and chronic with a high prevalence globally, and oral health is a primary component of human health sustenance. Oral health is associated with a wide variety of illnesses and disorders, including dental caries, periodontal disease, tooth loss, oral cancer, oral symptoms of HIV infection, oral-dental trauma, and birth defects such as noma and cleft lip. Oral diseases cause suffering and disability to millions of Americans, costing taxpayers billions of dollars annually, according to the Centers for Disease Control and Prevention (CDC).

\footnotetext{
*Correspondence: keum@snu.ac.kr; seockmo.ku@mtsu.edu

${ }^{1}$ Department of Food and Nutrition, and Research Institute of Human

Ecology, Seoul National University, Seoul 08826, Korea

${ }^{3}$ Fermentation Science Program, School of Agriculture, College of Basic and Applied Sciences, Middle Tennessee State University, Murfreesboro, TN 37132, USA

Full list of author information is available at the end of the article
}

According to a survey published in 2019, more than 40 percent of US adults report having felt pain in their mouths, and more than 80 percent have had at least one cavity by age 34. [1]. The 2015 Global Burden of Disease Survey estimated that about 3.5 billion people worldwide experience oral illnesses [2] and the World Health Organization (WHO) reports that millions of individuals suffer immensely from unhealthy oral cavities. Over the past 30 years, the global burden of tooth decay has remained largely unchanged and the total burden of oral disease will rise as a result of population growth and aging. Since the Tokyo Declaration on Dental Care and Oral Health for Healthy Lifetime, numerous oral health enhancement practices, including discussion of the overall value of oral health, the improvement of dental treatment systems, and the establishment of oral health programs, have been introduced by academia and industry [3]. 
Dental caries is caused by acid, formed by bacteria attached to the tooth's surface, which corrodes the enamel and dentine of teeth. Streptococcus mutans are Gram-positive, facultative anaerobic bacteria with a clear association with early dental caries in humans and animals. Insoluble glucan, combined by glucosyltransferase (GTase) in foods with sucrose and produced by $S$. mutans, has a high rate of adhesion to tooth and firm oral surfaces, and plays an important role in the development of dental caries. Oral microorganisms produce and attach glucans to oral surfaces, forming dental plaques and producing lactic acid (and others) during carbohydrate metabolism $[4,5]$.

Halitosis, defined as "stink through the mouth or nasal cavity" or "unpleasant odor from the mouth", is caused by volatile sulfur compounds (VSCs) such as hydrogen sulfide $\left(\mathrm{H}_{2} \mathrm{~S}\right)$ and methyl mercaptan $\left(\mathrm{CH}_{3} \mathrm{SH}\right)$ [6]. VSCs are produced by the decaying action of decomposing epithelial and white blood cells, which are eliminated by oral anaerobic bacteria. Volatile sulfur compounds are generated from sulfur-containing amino acids such as cysteine and methionine. Bacterial genera that produce hydrogen sulfide from cysteine include Peptostreptococcus, Eubacterium, Selenomonas, Centipeda, Bacteroides, Fusobacterium, and Prevotella, and genera that make methyl mercaptan from methionine are known to include Fusobacterium, Bacteroides, Porphyromonas, and Eubacterium $[6,7]$. F. nucleatum, for example, a major hydrogen sulfide or methyl mercaptan producing, Gram-negative anaerobic bacterium, causes periodontitis and halitosis.

Many studies have been published on the inhibition of harmful oral bacteria [8-11]. Antibiotics such as penicillin, erythromycin, and tetracycline are effective in the prevention of oral disease, but they have not been utilized due to the overall increase in antibiotic resistance by bacteria [12]. Other studies have sought to inhibit oral periodontal bacteria using natural materials $[11,13,14]$, inhibit GTase activity involving sucrose glucan formation [15], or use sucrose-alternative sweeteners that $S$. mutans is unable to metabolize [16]. Zinc ions, chlorhexidine $(\mathrm{CHX})$ and cetylpyridinium chloride $(\mathrm{CPC})$ and metal salts have been found to be effective in inhibiting the growth of halitosis-causing bacteria or in reducing the production of volatile sulfur compounds. Additionally, zinc chloride has been shown to mitigate halitosis by eliminating oral anaerobic bacteria [17]. Chlorhexidine, which is frequently used as a disinfectant in dental clinics, kills bacteria when applied to tooth enamel or the salivary pellicle and is widely used as a disinfectant in patients with periodontitis and to minimize halitosis [18]. Unfortunately, these strategies are not specific to harmful oral microorganisms or have a short period of action, making lasting effects difficult to achieve [19].
Microorganisms present in the oral cavity suppress the growth of fungi such as Candida, pathogenic microorganisms such as purulent bacteria, and viruses [20]. Therefore, a prevention strategy which suppresses the growth of all microorganisms present in the oral cavity is inappropriate for the prevention of oral disease. A healthy oral cavity can be maintained by promoting advantageous bacteria in the oral cavity and inhibiting bacteria that cause oral disease [21].

The Korean Ministry of Food and Drug Health requires manufacturers to submit information on the sources of microorganisms used in foods and drugs to allow for food product authorization and regulatory review for pharmaceutics. It has also developed a standard framework for quality assurance of these goods. The Korean National Institute of Food and Drug Safety Evaluation has also laid out standard guidelines for the quality assurance of probiotics products [23]. An estimation of the safety level of isolated bacteria for novel clinical probiotic use is important for the identification and elimination of possible clinical pathogens.

In this study, Lactobacillus spp. were evaluated as a means of controlling harmful oral microorganisms. Lactobacillus bacteria that inhibit the growth of harmful oral bacteria were collected from the saliva and feces of adults over 20 years of age. One individual species was isolated and identified, and safety tests were carried out following Food and Agriculture Organization of the United Nations (FAO)/World Health Organization (WHO)recommended studies and other published safety tests to verify its safety for academic and commercial applications [24].

\section{Materials and methods}

\section{Collection and isolation of lactic acid bacteria}

Samples of saliva were taken from 200 adults over 20 years of age with little or no supragingival plaque, enrolled in Seoul National University's Food Microbiological Research Laboratory (IRB No. 1907/003-018). Before brushing and before meals, samples were taken in the morning, combined with sterile 70 percent glycerol (1:1), and refrigerated until tested. Fecal samples were taken from 28 people over 20 years of age recruited from the Catholic University of Korea, Seoul St. Mary's Hospital (IRB KC17TNSI0570). Feces was collected in stool containers and stored frozen until analyzed. Lactobacillus colonies with excellent hydrogen peroxide production were selected using the process defined by Eschenbach et al. [25] and John F. T. Spencer [26]. In keeping with their methods, two solutions, $\mathrm{A}$ and $\mathrm{B}$, were prepared to add tetra methyl benzidine ( $3.3^{\prime}, 5.5^{\prime}$-tetra methyl benzidine or TMB) agar as a screening agent. Solution A consisted of $3 \mathrm{~mL}$ of DMSO (dimethyl sulfoxide, Sigma, St 
Louis, MO, USA) and $12.5 \mathrm{mg}$ of TMB (Sigma, St Louis, MO). Solution B $(0.5 \mathrm{mg} / \mathrm{mL}$ or $100 \mathrm{U} / \mathrm{mL}$ peroxidase) consisted of $1 \mathrm{~mL}$ of sterilized water and $0.5 \mathrm{mg}$ of peroxidase (Sigma, St Louis, MO, USA). de Man-RogosaSharpe (MRS, BD Difco ${ }^{\mathrm{TM}}$, Franklin Lakes, NJ, USA) agar was sterilized at $121{ }^{\circ} \mathrm{C}$ for $15 \mathrm{~min}$ and brought to 45 ${ }^{\circ} \mathrm{C}$. To create the final selective agar medium, $0.6 \mathrm{~mL}$ of Solution A and $0.2 \mathrm{~mL}$ of Solution B per $10 \mathrm{~mL}$ of MRS agar was added. The mixture was poured and allowed to solidify on plates. Each selection plate, therefore, had a concentration of $1 \mathrm{mM} \mathrm{TMB}$ and $10 \mu \mathrm{g} / \mathrm{mL}(2 \mathrm{U} / \mathrm{mL})$ of peroxidase.

To isolate lactic acid bacteria producing hydrogen peroxide, $100 \mu \mathrm{L}$ or $\mu \mathrm{g}$ of each obtained sample was diluted serially with sterilized phosphate buffered saline (PBS, pH 7.4). The diluted solution was then distributed across the TMB selective agar plates. After $48 \mathrm{~h}$ of anaerobic incubation at $37{ }^{\circ} \mathrm{C}$, the samples were exposed to 15-30 min of oxygen to allow for indicator response. Horseradish peroxidase induces oxidation of TMB by bacteria via the production of hydrogen peroxide, forming a blue colony. If the colony was blue, it was assessed as producing hydrogen peroxide $(+)$. Ten single colonies of blue color formed on each medium were randomly chosen for multiple streaking onto new TMB agar plates to separate 500 single colonies.

\section{Challenge and control bacterial strains and growth conditions}

Four oral anaerobic bacteria (Fusobacterium nucleatum KCOM 1001, Porphyromonas gingivalis KCOM 2796, Prevotella intermedia KCOM 2889, and Porphyromonas catoniae KCOM3169) and seven oral facultative anaerobic bacteria (Streptococcus sobrinus KCOM1157, Streptococcus mitis KCOM 1356, Streptococcus oralis KCOM 1493, Streptococcus gordonii KCOM 1788, Streptococcus sanguinis KCOM 2167, Streptococcus parasanguinis KCOM 2522, and Streptococcus mutans KCTC3065) from the Korean Collections of Oral Microbiology were utilized as challenge strains. F. nucleatum, P. gingivalis, $P$. intermedia, and P. catoniae KCOM3169 were individually incubated in KCOM broth (Brain Heart Infusion (BHI, BD Difco ${ }^{\mathrm{TM}}$, Franklin Lakes, NJ, USA) with $0.5 \%$ yeast extract (BD Difco ${ }^{\mathrm{TM}}$, Franklin Lakes, NJ, USA), 0.05\% Cysteine $\mathrm{HCl}-\mathrm{H}_{2} \mathrm{O}$ (Sigma, St Louis, MO, USA), 0.025\% Resazurin (Sigma, St Louis, MO, USA), $5 \mathrm{mg} / \mathrm{mL}$ Hemin solution (Sigma, St Louis, MO, USA), and $10 \mathrm{mg} /$ $\mathrm{mL}$ vitamin $\mathrm{K} 1$ solution (Sigma, St Louis, MO, USA) for $24 \mathrm{~h}$ at $37{ }^{\circ} \mathrm{C}$ under anaerobic conditions $\left(85 \% \mathrm{~N}_{2}, 10 \%\right.$ $\mathrm{H}_{2}, 5 \% \mathrm{CO}_{2}$ ). S. sobrinus KCOM1157, S. mitis KCOM 1356, S. oralis KCOM 1493, S. gordonii KCOM 1788, S. sanguinis KCOM 2167, S. parasanguinis KCOM 2522, and $S$. mutans KCTC3065 were individually grown in
BHI broth under aerobic conditions for $24 \mathrm{~h}$ at $37^{\circ} \mathrm{C}$ before use. Prior to use in each experiment, strains were subcultured twice in the appropriate medium. Weissella cibaria, a commercially available oral probiotic used as a Lactobacillus control in this study, was inoculated into MRS broth and incubated at $37^{\circ} \mathrm{C}$ for $24 \mathrm{~h}$ before use.

\section{Evaluation of the antibacterial effect of isolated lactic acid bacteria}

Fifty hydrogen peroxide producing Lactobacillus isolates were individually incubated at $37^{\circ} \mathrm{C}$ in $5 \mathrm{ml}$ of traditional MRS broth for $24 \mathrm{~h}$, and their supernatants were recovered by centrifugation at $4{ }^{\circ} \mathrm{C}$ for $5 \mathrm{~min}$ at $25,000 \times \mathrm{g}$. To remove the antimicrobial influence of organic acids, the supernatants were adjusted to $\mathrm{pH} 6.5 \sim 7$ with $1 \mathrm{M}$ syringe sterilized $(0.45 \mu \mathrm{m}) \mathrm{NaOH}$ and stored at $-20{ }^{\circ} \mathrm{C}$ before analysis. Two hundred $\mu \mathrm{L}$ of MRS broth was added to 96-well plates (SPL Life Sciences Co., Ltd. Pocheon, Korea) and the 11 oral microorganisms were inoculated at $1 \%$ into each well. Ten $\mu \mathrm{L}$ of each hydrogen peroxide producing Lactobacillus isolate supernatant was added to the wells seeded with oral microorganisms (final concentration 5\%) and the plates were anaerobically incubated at $37^{\circ} \mathrm{C}$. The wells were read at $600 \mathrm{~nm}$ for up to $24 \mathrm{~h}$ using a microplate reader (Epoch2, BioTek, Winooski, VT, USA) to determine the level of inhibition by the supernantant. One Lactobacillus isolate was designated as "HHuMIN D" based on its superior inhibition of oral microorganism growth. 16S rRNA sequencing was conducted to genetically identify the isolated bacteria, followed by base-sequence molecular phylogenetic analysis. The organism was identified as L. gasseri and named "L. gasseri HHuMIN D". For further experimental use, $L$. gasseri HHuMIN D was inoculated into MRS broth and incubated at $37^{\circ} \mathrm{C}$ for $24 \mathrm{~h}$. The culture broth of L. gasseri HHuMIN D was placed in $50 \%(\mathrm{v} / \mathrm{v})$ glycerol solution and stored at $-80^{\circ} \mathrm{C}$.

\section{Evaluation of the effect of $L$. gasseri HHuMIN D on oral microorganisms}

To test the impact of L. gasseri HHuMIN D on oral microorganisms, viable cell counts were carried out after co-culture using selective agar plates. The 11 challenge oral bacteria and L. gasseri HHuMIN D were inoculated at $5 \%$ in a $50 \% \mathrm{KCOM}$ broth $/ 50 \% \mathrm{BHI}$ broth medium in test tubes. The tubes were incubated at $37^{\circ} \mathrm{C}$ for $24 \mathrm{~h}$, followed by viable cell counts for each bacterium. All tubes were serially diluted after incubation; anaerobes were plated on KCOM agar, facultative anaerobes and anaerobes were plated on MSB agar (Mitis Salivarius Sucrose Bacitracin, Sigma-Aldrich, St. Louis, MO, USA), and L. gasseri HHuMIN D was plated on LBS agar (SigmaAldrich, St. Louis, MO, USA). This experiment was 
repeated three times, and the average value was determined after calculating the inhibition rate for each replication as $\%$ inhibition $=100 \times($ MAX - MIN $) /$ MAX (where MAX = viable cell count with no inhibition and $\mathrm{MIN}=$ viable cell count after co-culture).

\section{Hydrogen peroxide production test}

L. gasseri HHuMIN D culture medium, prepared as previously described, was centrifuged for $10 \mathrm{~min}$ at $4^{\circ} \mathrm{C}$ at $2000 \times \mathrm{g}$, and the supernatant extracted. Supernatants were colorimetrically analyzed using Pierce Quantitative Peroxide Assay Kits (aqueous-compatible formulation, Thermo Fisher Scientific, Waltham, MA, USA). Two hundred $\mu \mathrm{L}$ of working reagent (containing ammonium ferrous (II) sulfate, sorbitol, xylenol orange) and $20 \mu \mathrm{L}$ of L. gasseri HHuMIN D supernatant were placed into individual cells of a 96-well microplate and allowed to develop for fifteen minutes. A $1 \mathrm{mM}(1000 \mu \mathrm{M})$ solution of hydrogen peroxide was produced to standardize hydrogen peroxide production by diluting a $30 \%$ $\mathrm{H}_{2} \mathrm{O}_{2}$ supply $1: 9000\left(11 \mu \mathrm{L}\right.$ of $30 \% \mathrm{H}_{2} \mathrm{O}_{2}$ into $100 \mathrm{~mL}$ of ultrapure water). The $1 \mathrm{mM}$ hydrogen peroxide solution was then serially diluted $1: 2$ with sterile water $(100 \mu \mathrm{L}$ of sterile water $+100 \mu \mathrm{L}$ of $1 \mathrm{mM}$ hydrogen peroxide). Two hundred $\mu \mathrm{L}$ of the working reagent was then added to $20 \mu \mathrm{L}$ of the diluted $\mathrm{H}_{2} \mathrm{O}_{2}$ standard in microplate wells. prepared at a concentration of $20 \mathrm{mg} / \mathrm{mL}$. The enzymes were added to the culture supernatant at $10 \%(2 \mathrm{mg} / \mathrm{mL})$ and reacted at $37{ }^{\circ} \mathrm{C}$ for $150 \mathrm{~min}$ except for proteinase $\mathrm{K}$, which was reacted at $45{ }^{\circ} \mathrm{C}$ for $12 \mathrm{~h}$. The remaining bacteriocin activity was measured using a microtiter plate for oral harmful bacteria. A sample not treated with an enzyme solution under the same conditions was used as a negative control [27].

\section{Coaggregation assays}

L. gasseri HHuMIN D coaggregation was tested using the challenge microorganisms and a modified Handley et al. [28] spectrophotometric assay. L. gasseri HHuMIN D cells were harvested by centrifuging the culture medium at $4000 \times \mathrm{g}$ for $15 \mathrm{~min}$. Pellets were washed with Cisar's buffer three times and resuspended to approximately $10^{9}$ cells $/ \mathrm{mL}$. One $\mathrm{ml}$ of the coaggregation pairs were vortexed for $10 \mathrm{~s}$ and incubated with soft stirring at $110 \mathrm{rpm}$ at $37{ }^{\circ} \mathrm{C}$ for $30 \mathrm{~min}$. The coaggregations were then allowed to remain at room temperature for $3 \mathrm{~min}$ after incubation. One half $\mathrm{ml}$ of supernatant was removed from the culture and the optical density at $660 \mathrm{~nm}$ was determined using a microplate reader (Epoch2, BioTek, Winooski, VT, USA).

Coaggregation was determined using the decrease in absorbance vs. the control. The proportion of coaggregation was determined using the equation by Handley et al. (1987):

$$
\text { Coaggregation }(\%)=\frac{\mathrm{OD}_{660}(\mathrm{X} \text { control }+\mathrm{Y} \text { control }) / 2-\mathrm{OD}_{660}(\mathrm{X}+\mathrm{Y}) \times 100}{\mathrm{OD}_{660}(\mathrm{X} \text { control }+\mathrm{Y} \text { control }) / 2}
$$

The absorbance of both the L. gasseri HHuMIN D and hydrogen peroxide standard plate wells were assessed via microplate reader at $595 \mathrm{~nm}$ (Epoch2, BioTek, Winooski, VT, USA).

\section{Susceptibility assay of the bacteriocin produced by $L$. gasserie HHuMIN D to hydrolytic enzymes}

Proteins, carbohydrates and lipolytic enzymes were purchased from Sigma Aldrich (St. Louis, MO, USA) and used according to the manufacturer's instructions. Lipase $(4307 \mathrm{U} / \mathrm{mg})$ and trypsin $(13,50 \mathrm{U} / \mathrm{mg})$ in $50 \mathrm{mM}$ Tris- $\mathrm{HCl}$ buffer (pH 7.5), $\alpha$-chymotrypsin $(83.9 \mathrm{U} / \mathrm{mg}$ ) and carboxypeptidase $\mathrm{A}(73 \mathrm{U} / \mathrm{mg})$ in $50 \mathrm{mM}$ Tris- $\mathrm{HCl}$ (pH 8.0), pepsin $(3.280 \mathrm{U} / \mathrm{mg})$ in $10 \mathrm{mM}$ citrate $(\mathrm{pH}$ 6.0), $\alpha$-amylase $(519 \mathrm{U} / \mathrm{mg}$ ) in $0.1 \mathrm{M}$ sodium phosphate ( $\mathrm{pH} 7.0$ ) and proteinase $\mathrm{K}(30 \mathrm{U}) / \mathrm{mg}$ ) in $0.01 \mathrm{M}$ Tris$\mathrm{HCl}$ (pH 7.9), $0.05 \mathrm{M}$ EDTA and 0.5\% SDS buffer were where $\mathrm{X}$ control and $\mathrm{Y}$ control represent $\mathrm{OD}_{660}$ of the two microorganisms in the control tubes and $(\mathrm{X}+\mathrm{Y})$ is the mixture of organisms.

\section{Effect of $L$. gasseri HHuMIN D on the formation of artificial dental plaque by $S$. mutans}

To assess whether and the degree to which $L$. gasseri HHuMIN D prevents the development of artificial dental plaque by $S$. mutans, beaker wire tests following the protocol of Yu et al. [29] were conducted. Five percent sucrose was added to $40 \mathrm{ml}$ of broth consisting of equivalent quantities of $\mathrm{BHI}$ and MRS broth and the $\mathrm{pH}$ was adjusted to 7.0 by the addition of $0.1 \mathrm{M}$ MOPS buffer. The medium was inoculated with $1 \times 10^{8} \mathrm{~S}$. mutans and $1 \times 10^{8}$ L. gasseri HHuMIN D cells alone or combination. Stainless steel orthodontic wires $(4 \mathrm{~cm}$ length, 0.016inch, $1 \mathrm{~mm}$ dia, Oramco, Glendora, CA, USA) were suspended on conical tubing and immersed in the broth. The weights of the artificial dental plaques produced on the wires were calculated after $12 \mathrm{~h}$ of incubation at $37^{\circ} \mathrm{C}$ while shaking at $30 \mathrm{rpm}$. 


\section{Adhesion assay of $L$. gasseri HHuMIN D}

$\mathrm{KB}$ cell line oral epithelial cells (KCLB 10,017) were acquired from the Cell Line Bank of Korea (Seoul, Korea). KB cells were cultured in RPMI-1640 Media (SigmaAldrich, St. Louis, MO, USA) containing 10\% (v/v) fetal bovine serum (FBS, Sigma-Aldrich, St. Louis, MO, USA) and $1 \%(\mathrm{v} / \mathrm{v})$ antibiotic-antimycotic solution (SigmaAldrich, St. Louis, MO, USA) in $5 \% \mathrm{CO}_{2}$ at $37{ }^{\circ} \mathrm{C}$. For the adhesion efficiency assay, $\mathrm{KB}$ cells were inoculated into a minimum critical medium (MEM, Sigma-Aldrich, St. Louis, MO, USA) containing 10 percent (v/v) FBS at $110^{5}$ cells/well. Upon transfer to a 24-well multi-culture dish (Thermo Fisher Scientific, St Peters, MO, USA), the cells were grown for $18 \mathrm{~h}$ at $5 \% \mathrm{CO}_{2}$ at $37{ }^{\circ} \mathrm{C}$.

L. gasseri HHuMIN D was grown for $18 \mathrm{~h}$ in MRS broth at $37^{\circ} \mathrm{C}$ and the bacterial concentration was adjusted to $10^{8} \mathrm{CFU} / \mathrm{mL}$ (measured at $600 \mathrm{~nm}$ ). Isolated bacteria were centrifuged at $8000 \times \mathrm{g}$ for $3 \mathrm{~min}$ and washed with PBS three times. The washed bacteria were then resuspended in MEM media. The number of cells measured by hemocytometer (Paul Marienfeld, Lauda-Königshofen, Germany) was about 6 log cells per well.

L. gasseri HHuMIN D cells were then added to the 24-well culture dish cells containing KB cells at about 6 $\log$ cells per well and incubated for $1 \mathrm{~h}$ at $37{ }^{\circ} \mathrm{C}$ and $5 \%$ $\mathrm{CO}_{2}$. The suspension was eliminated after incubation and the 24-well plates were washed two times with PBS (pH 7.4). For $10 \mathrm{~min}, 200 \mu \mathrm{L}$ trypsin/EDTA (Welgene, Daegu, Korea) was applied to the cell monolayer, and the cells and attached bacteria were collected. MG cell Genomic DNA Extraction SV kits (Doctor Protein, Seoul, Korea) were used to remove the genomic DNA (gDNA) of the attached bacteria in the extracted pellets. Pending analysis, the final volume of all DNA samples $(200 \mu \mathrm{L})$ was stored at $-20{ }^{\circ} \mathrm{C}$. The number of bacteria adhered to the KB cells was determined using qRT-PCR.

Protection and displacement assays were conducted to assess the competition between L. gasseri HHuMIN $\mathrm{D}$ and harmful oral bacteria (F. nucleatum and $S$. mutans) for cell adhesion using modified versions of a previously reported process [30]. In protection assays, $1 \mathrm{~mL}\left(110^{8} \mathrm{CFU} / \mathrm{mL}\right)$ of L. gasseri HHuMIN D was applied to 24-well culture dishes loaded with $\mathrm{KB}$ cells and incubated for $1 \mathrm{~h}$ at $37{ }^{\circ} \mathrm{C}$ and $5 \% \mathrm{CO}_{2}$ for $1 \mathrm{~h}$. The suspension was removed after incubation, and the cell monolayer was washed twice with PBS. Next, $1 \mathrm{~mL}$ $\left(110^{8} \mathrm{CFU} / \mathrm{mL}\right)$ of a harmful oral bacteria suspension (F. nucleatum and S. mutans) was applied to the wells and incubated for $1 \mathrm{~h}$ at $37^{\circ} \mathrm{C}$ and $5 \% \mathrm{CO}_{2}$. The suspension was removed, and the cell monolayer was washed twice with PBS. Two hundred $\mu \mathrm{L}$ of trypsin/EDTA (Welgene, Daegu, Korea) was added to the KB cell monolayer and allowed to stand for $10 \mathrm{~min}$, after which the $\mathrm{KB}$ cells and attached bacteria were gathered.

In displacement assays, $1 \mathrm{~mL}\left(110^{8} \mathrm{CFU} / \mathrm{mL}\right)$ of a harmful oral bacteria suspension ( $F$. nucleatum and $S$. mutans) was applied to 24-well KB cells and incubated for $1 \mathrm{~h}$ at $37{ }^{\circ} \mathrm{C}$ and $5 \% \mathrm{CO}_{2}$ for $1 \mathrm{~h}$. The suspension was removed after incubation and the monolayer cell was washed twice with PBS. Next, $1 \mathrm{~mL}\left(110^{8} \mathrm{CFU} / \mathrm{mL}\right)$ of L. gasseri HHuMIN D was applied to the wells and incubated for $1 \mathrm{~h}$ at $37^{\circ} \mathrm{C}$ and $5 \% \mathrm{CO}_{2}$. After the second inoculation, the experimental procedure was the same as for the protection assays.

KB cells attached only to $F$. nucleatum and $S$. mutans were used as controls. The number of bacteria appended to each KB cell was determined using realtime PCR.

The collected gDNA was used to quantitatively analyze each bacterium that was attached to the KB cells using real-time PCR. Standard curves were drawn using bacterium-specific primers, and the bacteria were quantified to test cell adhesion from the extracted DNA. A standard curve was drawn using primers specific to each bacterium, and bacteria were quantified from the extracted DNA to measure cell adhesion. The primers used to amplify the bacteria are shown in Table 1. Real-time PCR was conducted on 96-well plates (SPL Life Sciences Co., Ltd. Pocheon, Korea) using tepOnePlus ${ }^{\mathrm{TM}}$ Real Time PCR systems (Thermo Fisher Science, St Peters, MO, USA). The PCR reaction was performed using $1 \times \mathrm{TB}_{\text {Green }}{ }^{\mathrm{TM}}$ Premix Ex Taq ${ }^{\mathrm{TM}}$ (Takara, Japan), and real-time PCR conditions are as follows; the first denaturation for $10 \mathrm{~min}$ at $95{ }^{\circ} \mathrm{C}$, and

Table 1 Oligonucleotides used as primers for real-time PCR

\begin{tabular}{|c|c|c|c|c|}
\hline \multirow{2}{*}{$\begin{array}{l}\text { Bacteria name } \\
\text { Lactobacillus }\end{array}$} & \multicolumn{2}{|c|}{ Oligonucleotide sequence } & \multirow{2}{*}{$\begin{array}{l}\text { Length } \\
21\end{array}$} & \multirow{2}{*}{$\begin{array}{l}\text { Reference } \\
{[102]}\end{array}$} \\
\hline & Forward & TGG AAA CAG RTG CTA ATA CCG & & \\
\hline & Reverse & GTC CAT TGT GGA AGA TTC CC & 20 & \\
\hline \multirow[t]{2}{*}{ Fusobacterium nucleatum } & Forward & AGA GTTTGA TCC TGG CTC AG & 20 & [103] \\
\hline & Reverse & GTC ATC GTG CAC ACA GAA TTG CTG & 24 & \\
\hline \multirow[t]{2}{*}{ Streptococcus mutans } & Forward & CTA CAC TTT CGG GTG GCT TG & 20 & {$[104]$} \\
\hline & Reverse & GAA GCT TTT CAC CATTAG AAG CTG & 24 & \\
\hline
\end{tabular}


then 40 polymerase chain reaction cycles at $95{ }^{\circ} \mathrm{C}$ for $15 \mathrm{~s}$ and $60^{\circ} \mathrm{C}$ for $1 \mathrm{~min}$. Analysis of the results was carried out using StepOne ${ }^{\mathrm{TM}}$ and StepOnePlus ${ }^{\mathrm{TM}}$ Software v2.3 (Thermo Fisher Scientific, St Peters, MO, USA). The number of bacteria was calculated by converting the value of the cycle threshold (CT) into the standard curve.

\section{Safety assessment of L. gasseri HHuMIN D Ammonia production testing}

The catalyzed indophenol reaction [31] ammonia production test was utilized. L. gasseri HHuMIN D cells were cultured anaerobically in BHI media at $37{ }^{\circ} \mathrm{C}$ for 5 days, after which the culture medium was centrifuged (2236R centrifuge; Labogene Aps, Lillerød, Denmark) at $10,000 \times \mathrm{g}$ for $30 \mathrm{~min}$ to isolate the supernatant. The supernatant was adjusted after extraction to $\mathrm{pH}$ 7.0.

Two solutions were prepared: Solution A consisted of $0.01 \mathrm{~g}$ of sodium nitroferricyanide dihydrate (Sigma, St. Louis, MO, USA) and $2 \mathrm{~g}$ of phenol (Sigma, St. Louis, MO, USA) in $200 \mathrm{~mL}$ LC-MS grade water, and Solution $\mathrm{B}$ consisted of $1 \mathrm{~g}$ of sodium hydroxide and $0.08 \mathrm{~g}$ of sodium hypochlorite in $200 \mathrm{~mL}$ LC-MS grade water. One hundred $\mu \mathrm{L}$ of $L$. gasseri HHuMIN D supernatant was dispensed into 96-well plates, followed by $10 \mu \mathrm{L}$ each of solutions $\mathrm{A}$ and $\mathrm{B}$, and incubated for $1 \mathrm{~h}$ at $20^{\circ} \mathrm{C}$. Using a microplate reader (Bio-Rad Laboratories, Philadelphia, PA, USA) the optical density was measured at $625 \mathrm{~nm}$. Uninoculated BHI medium was used as a control and a standard curve was used to measure ammonia concentration. Enterococcus faecium ATCC19433 supernatant was employed as a positive control.

\section{Biogenic amine production testing}

Biogenic amine analysis was conducted using the method of Kim et al. [32]. Four biogenic amines, cadaverine ( $\geqq$ $97.0 \%$ ), histamine ( $\geqq 97.0 \%)$, putrescine ( $\geqq 98.5 \%)$, and tyramine ( $\geqq 99.0 \%$ ), were purchased from Sigma-Aldrich (St. Louis, MO, USA), as were 1.7-diaminoheptane (internal standard; ISTD, 98\%, Cat. \# D174708), dansyl chloride ( $\geq 99.0 \%$, Cat. \# 39,220), and L-proline ( $\geq 99.0 \%$, Cat. \# P0380). Whatman No. 4 filter paper was purchased from Whatman Intl., Ltd (Maidstone, UK). Sodium carbonate $(99.0 \%$, Cat. \# 433,401,201), ether $(99.0 \%$, Cat. \# 33475S1280), and acetone (99.7\%, Cat. \# A0108) were purchased from Samchun Pure Chemical Co., Ltd. (Pyeongtaek, Korea).

L. gasseri HHuMIN D was grown anaerobically in MRS broth with 0.05 percent (w/w) L-cysteine-HCl (Sigma, St. Louis, MO, USA) at $37^{\circ} \mathrm{C}$ for $18 \mathrm{~h}$. Next, $25 \mathrm{~mL} 0.1 \mathrm{~N}$ $\mathrm{HCl}$ was added to $5 \mathrm{~mL}$ of L. gasseri HHuMIN D supernatant and blended for $5 \mathrm{~min}$. The supernatant was separated by centrifugation (2236 R centrifuge; Labogene Aps, Lillerød, Denmark) at $10,000 \times \mathrm{g}$ for $15 \mathrm{~min}$. The gathered supernatant was filtered through a $20-25 \mu \mathrm{m}$ membrane filter (Whatman Int'l., Ltd., Maidstone, UK) and $1 \mathrm{~mL}$ of filtrate was combined with $0.1 \mathrm{~mL}$ of $0.01 \%$ $(\mathrm{w} / \mathrm{v})$ 1.7-diaminoheptane, $0.5 \mathrm{~mL}$ of saturated sodium carbonate solution, and $1 \mathrm{~mL}$ of $1 \%$ dansyl chloride. The mixture was incubated in a water bath (WBC 1510A; Jeio Tech. Co., Ltd., Seoul, Korea) after thorough mixing, with light blocked at $45^{\circ} \mathrm{C}$ for $1 \mathrm{~h}$. By adding $0.5 \mathrm{~mL}$ of 10 percent proline and $5 \mathrm{~mL}$ diethyl ether at room temperature and allowing it to stand for $5 \mathrm{~min}$, the remaining dansyl chloride was removed. The supernatant was concentrated using a Scanvac Speed Vacuum Concentrator (Labogene Aps, Lillerød, Denmark) at $1500 \mathrm{rpm}$ and $20^{\circ} \mathrm{C}$ until dry for high performance liquid chromatography (HPLC) analysis. Next, the dry pellets were resuspended in $1 \mathrm{~mL}$ of acetonitrile (Sigma-Aldrich, St. Louis, MO, US). After filtering through a $0.22-\mu \mathrm{m}$ filter membrane, the resuspended sample and standard were analyzed. A Thermo Dionex Ultimate 3000 HPLC (Thermo Fisher Scientific, St Peters, MO, USA) with a VDSpher C-18 column (4.6 $250 \mathrm{~mm}, 5 \mu \mathrm{m}$ ) (VDS Optilab Chromatographie Technik $\mathrm{GmbH}$, Berlin, Germany) was used to analyze the samples. The mobile phase was (A) acetonitrile, (B) distilled water $(0-1 \min , \mathrm{A}: \mathrm{B}=40: 60 ; 1-25 \min , \mathrm{A}: \mathrm{B}=100$ : 0 ; 25-35 min, $A: B=60: 40$ ). The injection volume was 20 $\mu \mathrm{L}$, the flow rate was $0.8 \mathrm{~mL} / \mathrm{min}$, the column temperature was $30{ }^{\circ} \mathrm{C}$ (constant), and the UV detection wavelength was $250 \mathrm{~nm}$.

\section{Hemolysis testing}

Hemolysis testing was conducted according to the method of Kim et al. [32]. Hemolysis was observed by anaerobic incubation of $L$. gasseri HHuMIN D in BL agar (BD Difco ${ }^{\mathrm{TM}}$, Franklin Lakes, NJ, USA) for 2 days at $37^{\circ} \mathrm{C}$ with $5 \%$ sheep blood. As a positive control, Listeria ivanovii subsp. ivanovii ATCC 19,119 was incubated on the same agar for 2 days under aerobic conditions at $37{ }^{\circ} \mathrm{C}$. The presence or absence of light visible through both sides of the plates indicated hemolysis. Strains that did not produce green areas around the colonies $(\alpha$-hemolysis) or did not cause hemolysis in the blood plate $(\gamma$-hemolysis) were considered nonhemolytic. Strains having a clear zone around the colonies were classified as $\beta$-hemolytic bacteria.

\section{Mucin degradation testing}

The degradation of mucins was estimated using the method of Kim et al. [32]. Type III porcine stomach mucin was purchased from Sigma-Aldrich (St. Louis, MO, USA). As a negative control, MRS medium was used without a carbon source. Four MRS broths with 
different carbon sources were prepared: $0.5 \%(\mathrm{w} / \mathrm{v})$ mucin, $1.0 \%(\mathrm{w} / \mathrm{v})$ mucin, $0.5 \%(\mathrm{w} / \mathrm{v})$ glucose, and $1 \%$ (w/v) glucose. Each broth was inoculated with L. gasseri HHuMIN D and anaerobically incubated 2 days at $37^{\circ} \mathrm{C}$. Strain growth was estimated using a microplate reader (Bio-Rad Laboratories, Philadelphia, PA, USA) at $0,12,24,36$, and $48 \mathrm{~h}$ by measuring the optical density at $550 \mathrm{~nm}$. By subtracting the final optical density value of each sample from the original optical density value, the growth in each broth was determined.

\section{Antimicrobial susceptibility testing}

Antibiotic resistance may be present in Lactobacillus spp. [33] and since antibiotic resistance can be transmitted via plasmids, the evaluation of antibiotic resistance is an important consideration for their safety assessment [34]. L. gasseri HHuMIN D antimicrobial susceptibility was estimated using the method of Kim et al. [32]. Twenty-three antimicrobial compounds were tested in this experiment: ampicillin sodium salt, bacitracin, carbenicillin disodium salt, cephalothin sodium salt, chloramphenicol, clindamycin hydrochloride, dicloxacillin sodium salt hydrate, erythromycin, gentamicin sulfate, kanamycin sulfate, lincomycin, methicillin, metronidazole, mupirocin, neomycin sulfate, penicillin G, phosphomycin disodium salt, polymyxin B sulfate salt, rifampicin, streptomycin sulfate salt, tetracycline, trimethoprim-sulfamethoxazole (trimethoprim), and vancomycin hydrochloride.

All antimicrobials were purchased from Sigma (St. Louis, MO, USA) except vancomycin hydrochloride, which was purchased from USP, Bethesda, Maryland, USA. Before being added to LSM-Cys broth (LAB susceptibility test medium with L-cysteine, consisting of 90 percent IST and 10 percent MRS broth medium), each antibiotic powder was dissolved in a suitable diluent, sterilized and filtered. IST was purchased from Kisan Bio Co., Ltd. (Mb cell I so-Sensitest Broth, Seoul, Korea), and MRS was purchased from Becton, Dickinson and Company (BD Difco ${ }^{\mathrm{TM}}$ MRS Lactobacilli broth, Franklin Lakes, NJ, USA). The ISO10932: 2010 minimal inhibitory concentration (MIC) values for the 20 antibiotics tested on L. gasseri HHuMIN D were used.

1. For this experiment, LSM-Cys (LAB susceptibility test) medium containing $0.03 \%(\mathrm{w} / \mathrm{v})$ L-cysteine $\mathrm{HCl}$ was used with 96-well plates. Upon diluting serially twice, the antibiotic broth used ranged from $0.0032-1024 \mathrm{~g} / \mathrm{mL}$. Finally, the microorganisms were inoculated at a rate of $0.2 \%$ (the final concentration was approximately $310^{8} \mathrm{cfu} / \mathrm{mL}$ ) in the LSM-Cys media and $50 \mu \mathrm{L}$ of each diluted medium was inoculated into each well. There was no negative control. The dilute medium was anaerobically incubated at $37{ }^{\circ} \mathrm{C}$ for $48 \mathrm{~h}$. The MIC was visually determined by comparing the test samples to the control; antibiotic susceptibility was considered to be the prevention of bacterial growth by $80 \%$ or more.

\section{Complete genome sequencing, assembly, and annotation of $L$. gasseri HHuMIN D}

Chunlab, Inc. (Seoul, Korea), which used PacBio Sequel Systems (Pacific Biosciences, Menlo Park, CA, USA) and CLgenomicsTM and EZBioCloud Apps services (Chunlab, Seoul, Korea), conducted whole genome sequencing of L. gasseri HHuMIN D. General gene information was investigated by EZBiodCloud Apps and functional annotations for the expected genes were analyzed using RefSeq protein (NR; NCBI), Clusters of Orthologous Groups of proteins (COG), EggNOG, SEED, Swiss-Prot, and Kyoto Encyclopedia of Genes and Genomes (KEGG) databases [35-38].

\section{Safety evaluation with complete genome sequence}

Analysis of virulence factors was carried out through the VirulenceFinder 2.0 Website, which is a part of the openly accessible web-based tool for whole genome sequencing (WGS) analysis hosted by the Center for Genomic Epidemiology (CGE, http://www.genomicepidemiology.org/, 2014). The predicted L. gasseri HHuMIN D genes were compared with the comprehensive antibiotic resistance database (CARD, http://arpcard.mcmaster.ca) for identifying antibiotic resistance (https://card.mcmaster.ca). The ability to synthesize biogenic amines and aggregate platelets was searched using full genome sequencing of L. gasseri HHuMIN D via CLGenomics (ChunLab, Seoul, South Korea, 2004) through matching with the KEGG pathway.

\section{Statistical analysis}

Data are expressed as mean \pm SEM by SPSS software (IBM SPSS Statistics, Version 25, SPSS Inc., Chicago, IL, USA). Differences between the means were measured by one-way ANOVA using Duncan's multiple range test. Statistical significance was assumed at $p<0.05$. 


\section{Results and discussion}

Identification of hydrogen peroxide-generating lactobacilli The screening of Lactobacillus progressed in a three-step process. First, 500 strains with excellent development of hydrogen peroxide were isolated from saliva and feces. Second, Lactobacillus sp. were collected using LBS agar plates to sort through the 500 isolated strains. A total of 50 isolates were identified. Finally, the 50 isolates were tested for their strength against oral microorganisms, and HHuMIN D was the most effective.

The antimicrobial effect of $5 \%$ of HHuMIN D supernatant was clearly demonstrated in the control of anaerobic oral bacteria causing halitosis. P. catoniae, P. intermedia, F. nucleatum, and P. gingivalis were inhibited by 90 , $89 \pm 1,88 \pm 1$, and $88 \pm 1 \%$, respectively. S. mutans, a dental caries-inducing bacterium, was inhibited by $60 \pm 2 \%$. S. mitis and S. gordonii, which cause periodontitis, were inhibited by $22 \pm 2$ and $19 \pm 5 \%$, respectively. Antimicrobial activity was lower against oral facultative anaerobic bacteria (S. sobrinus, S. sanguinis, S. parasanguinis, and S. oralis). On the other hand, the antimicrobial effect of $5 \%$ of $W$. cibaria culture supernatant showed

Table 2 Inhibition of periodontal bacteria by L. gasseri HHuMIN D supernatant

\begin{tabular}{lcc}
\hline Strains & \multicolumn{2}{l}{ Inhibition (\%) } \\
\cline { 2 - 3 } & W. cibaria & L.gasseri HHuMIN D \\
\hline Fusobacterium nucleatum KCOM 1001 & $5 \pm 1^{\mathrm{a}}$ & $\mathbf{8 8} \pm \mathbf{1}^{\mathrm{a}}$ \\
Porphyromonas gingivalis KCOM 2796 & $11 \pm 3^{\mathrm{a}}$ & $\mathbf{8 8} \pm \mathbf{1}^{\mathrm{a}}$ \\
Prevotella intermedia KCOM 2889 & $13 \pm 1^{\mathrm{a}}$ & $\mathbf{8 9} \pm \mathbf{1}^{\mathrm{a}}$ \\
Porphyromonas catoniae KCOM3169 & $14 \pm 2^{\mathrm{a}}$ & $\mathbf{9 0} \pm \mathbf{0}^{\mathrm{a}}$ \\
Streptococcus sobrinus KCOM1157 & $8 \pm 1^{\mathrm{a}}$ & $\mathbf{6 0} \pm \mathbf{2}^{\mathrm{b}}$ \\
Streptococcus mitis KCOM 1356 & $17 \pm 2^{\mathrm{b}}$ & $4 \pm 4^{\mathrm{c}}$ \\
Streptococcus oralis KCOM 1493 & $22 \pm 5^{\mathrm{b}}$ & $4 \pm 6^{\mathrm{c}}$ \\
Streptococcus gordonii KCOM 1788 & $0 \pm 0^{\mathrm{c}}$ & $19 \pm 5^{\mathrm{d}}$ \\
Streptococcus sanguinis KCOM 2167 & $0 \pm 0^{\mathrm{c}}$ & $2 \pm 3^{\mathrm{c}}$ \\
Streptococcus parasanguinis KCOM & $12 \pm 3^{\mathrm{a}}$ & $2 \pm 2^{\mathrm{c}}$ \\
2522 & & \\
Streptococcus mutans KCTC3065 & $0 \pm 0^{\mathrm{c}}$ & $22 \pm 2^{\mathrm{d}}$ \\
\hline
\end{tabular}

Values are expressed as the mean \pm standard deviation. Means not sharing a common letter are significantly different groups at $p<0.001(n=3)$ relatively weaker antimicrobial activity than HHuMIN D (Table 2).

Lactobacillus culture medium neutralization and disinfection is an experimental process used to monitor the antibacterial activity of bacteria metabolites, such as bacteriocin. In another study, sterile neutral S. mutans ATCC 25,175 supernatant showed $>80 \%$ inhibition of L. paracasei strains [39]. Another study confirmed that Lactobacillus gasseri, which produces gassericin A, has inhibitory properties against a wide range of oral pathogens, including carcinogenic and periodontal pathogens [40].

HHuMIN D was shown to produce hydrogen peroxide and suppress oral microorganisms. 16S rRNA gene sequencing of HHuMIN D showed that it is a Lactobacillus sp. Multiple alignment of $16 \mathrm{~S}$ rRNA base sequences of isolated bacteria with the Lactobacillus sp. 16S rRNA sequence was obtained through the similarity matrix listed on GenBank. This genealogy research showed a 99\% 16S rRNA homology; HHuMIN D shares 99\% homology with L. gasseri (Fig. 1).

Lactobacillus species isolated from the oral cavity vary widely. Lactic acid bacteria such as L. acidophilus, $L$. casei, L. fermentum, L. gasseri, L. johnsonii, L. rhamnosus, L. reuteri, L. salivarius and L. vaginalis are probiotic strains commonly used in dairy and health/functional food products [41-44]. The current research confirms that candidate probiotic Lactobacillus strains are present in the oral cavity and the probiotic capabilities of L. gasseri HHuMIN D.

\section{Inhibition effect of L. gasseri HHuMIN D on oral microorganisms}

Oral lactic acid bacteria are known to inhibit harmful oral bacteria by the production of various antibiotics [45]. L. gasseri has been studied as an oral probiotic and results have shown that it is effective against harmful oral bacteria $[46,47]$.

The interactions between L. gasseri HHuMIN D and oral anaerobic and facultative anaerobic bacteria are shown in Fig. 2. All harmful oral bacteria were strongly inhibited by L. gasseri HHuMIN D, but interaction with oral microorganisms also impaired its proliferation. Compared to single culture, L. gasseri HHuMIN D showed poor growth in most co-cultures. Among them,

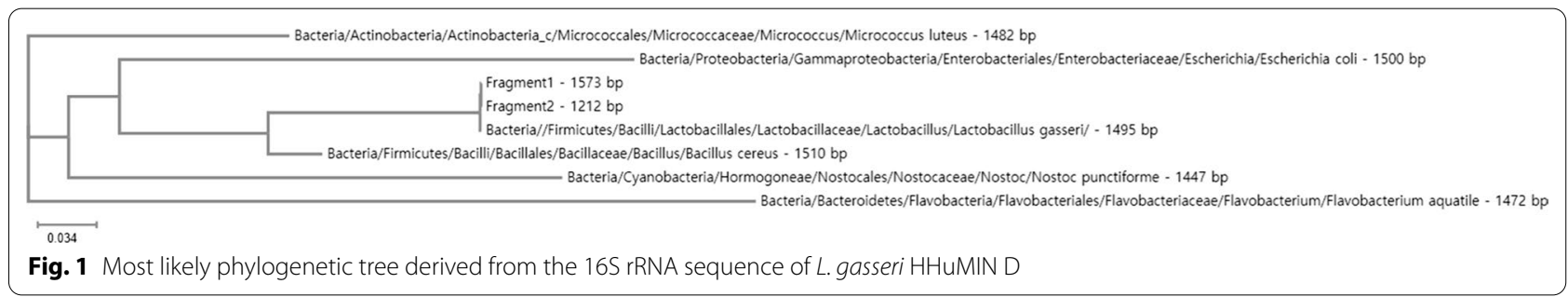




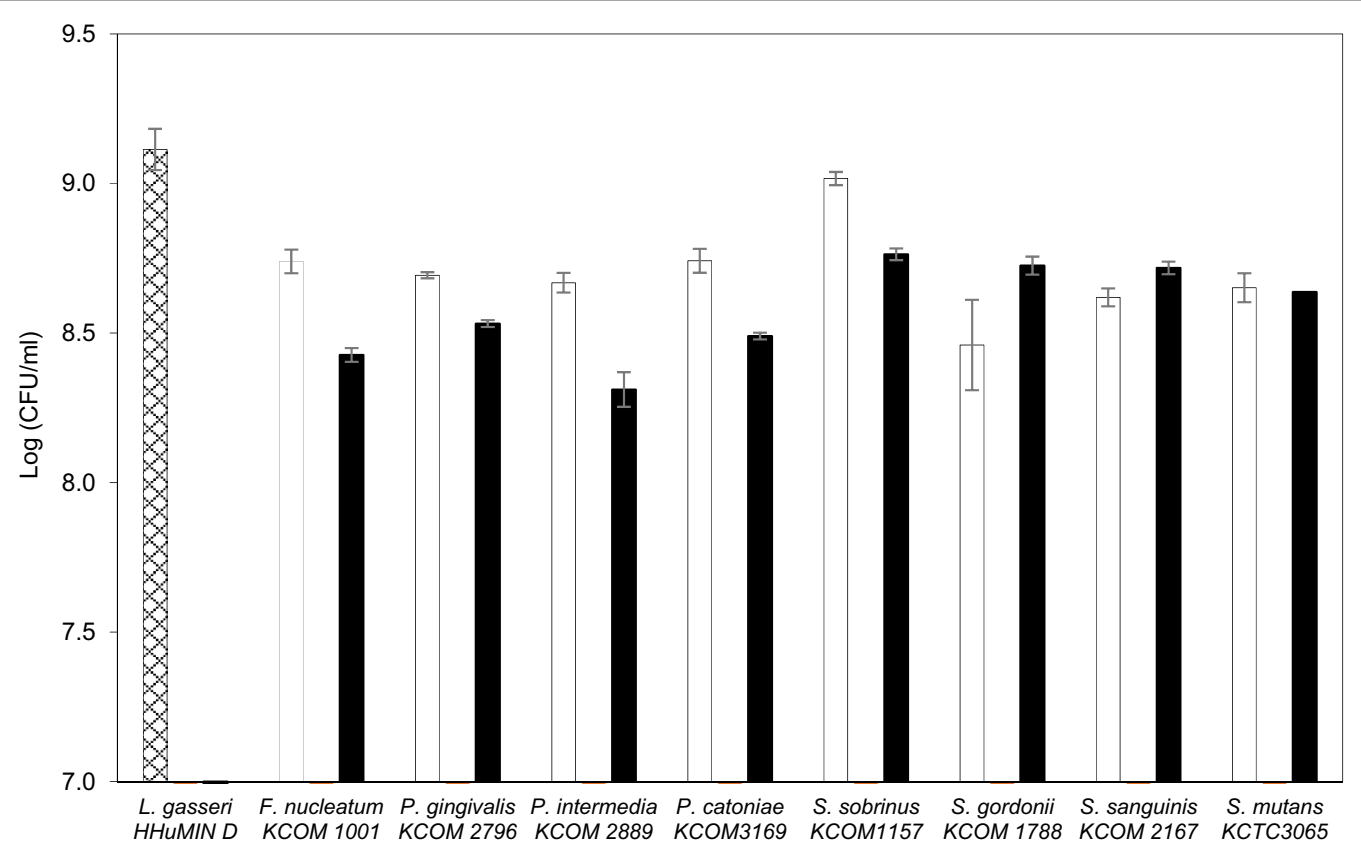

Fig. 2 Inhibitory effect of L. gasseri HHuMIN D on the proliferation of various periodontal bacteria. 图, L. gasseri HHuMIN D; $\square$, Periodontal bacteria group; , Periodontal bacteria in mixed culture; $\mathbf{\square}$ L. gasseri HHuMIN D in mixed culture. Log 7 and below means $<10^{5}$

the lowest viable cell counts occurred when L. gasseri HHuMIN D was co-cultured with $P$. intermedia.

A previous study on the co-culture of oral anaerobia (F. nucleatum, P. gingivalis) and beneficial oral bacteria (Weissella cibaria) showed that $F$. nucleatum reduced the number of viable cells up to $1.510^{8} \mathrm{CFU} / \mathrm{mL}$, and $P$. gingivalis reduced the number of viable cells to $<10^{5} \mathrm{CFU} /$ $\mathrm{mL}$, compared to controls [19]. In this experiment L. gasseri HHuMIN D inhibited $F$. nucleatum more effectively. Additionally, L. gasseri HHuMIN D inhibited P. intermedia, $P$. catoniae and seven facultative anaerobic bacteria quite effectively.

In another study, Lactobacillus salivarius, Lactobacillus fermentum, and the fermentation broths of these bacteria showed a definite inhibitory effect against harmful periodontal bacteria. Lactobacillus spp. showed greater direct antibacterial effects against harmful oral bacteria than their microbial supernatants. As the number of lactic acid bacteria and the concentration of the fermentation broth increased, the antibacterial effect also increased [48]. The current research results are similar to those of Chen et al. (2012): L. gasseri HHuMIN D's antibacterial effect was greater than L. gasseri HHuMIN D's supernatant antibacterial effect. This indicates the direct inhibition of harmful bacteria by L. gasseri HHuMIN D and indirect inhibition by the metabolites it produces [21, 43]. L. gasseri HHuMIN D strongly inhibited all harmful oral bacteria, but the supernatant of this bacteria inhibited only anaerobic oral bacteria and had different effects. The combination of these two actions efficiently kills pathogenic microorganisms in the oral environment [43]. L. gasseri HHuMIN D may, therefore, mitigate oral diseases caused by harmful oral bacteria.

\section{Accumulation of hydrogen peroxide by L. gasseri HHuMIN D}

Oral Lactobacillus spp. produces bacteriocins, lactic acid and hydrogen peroxide, which act as a defense against pathogens [22, 49]. The generation of hydrogen peroxide is a typical function of Lactobacillus spp. ( $L$. bulgaricus, L. lactis, and L. plantarum) isolated from the oral cavity. Several studies have shown that these beneficial bacteria inhibit the growth of pathogenic microorganisms such as Staphylococcus aureus [50], Pseudomonas spp. [51], and psychrotrophic bacteria $[52,53]$. The hydrogen peroxide produced by L. gasseri HHuMIN D increased continuously from $0 \mu \mathrm{mol} / \mathrm{L}$ to $802 \mu \mathrm{mol} / \mathrm{L}$ after $3 \mathrm{~h}$ (Fig. 3). After $12 \mathrm{~h}$, the concentration of hydrogen peroxide decreased steadily to 24 h. L. johnsonii and L. gasseri have been shown to produce hydrogen peroxide at rates between 400 and $1400 \mu \mathrm{mol} / \mathrm{L}$ [54]. Other research found that $S$. sanguis released hydrogen peroxide up to $30 \mu \mathrm{mol} / \mathrm{L}, S$. oralis released hydrogen peroxide up to $640 \mu \mathrm{mol} / \mathrm{L}$ and both inhibited plaque formation by inhibiting $S$. mutans proliferation. The application of lactoperoxidase and 


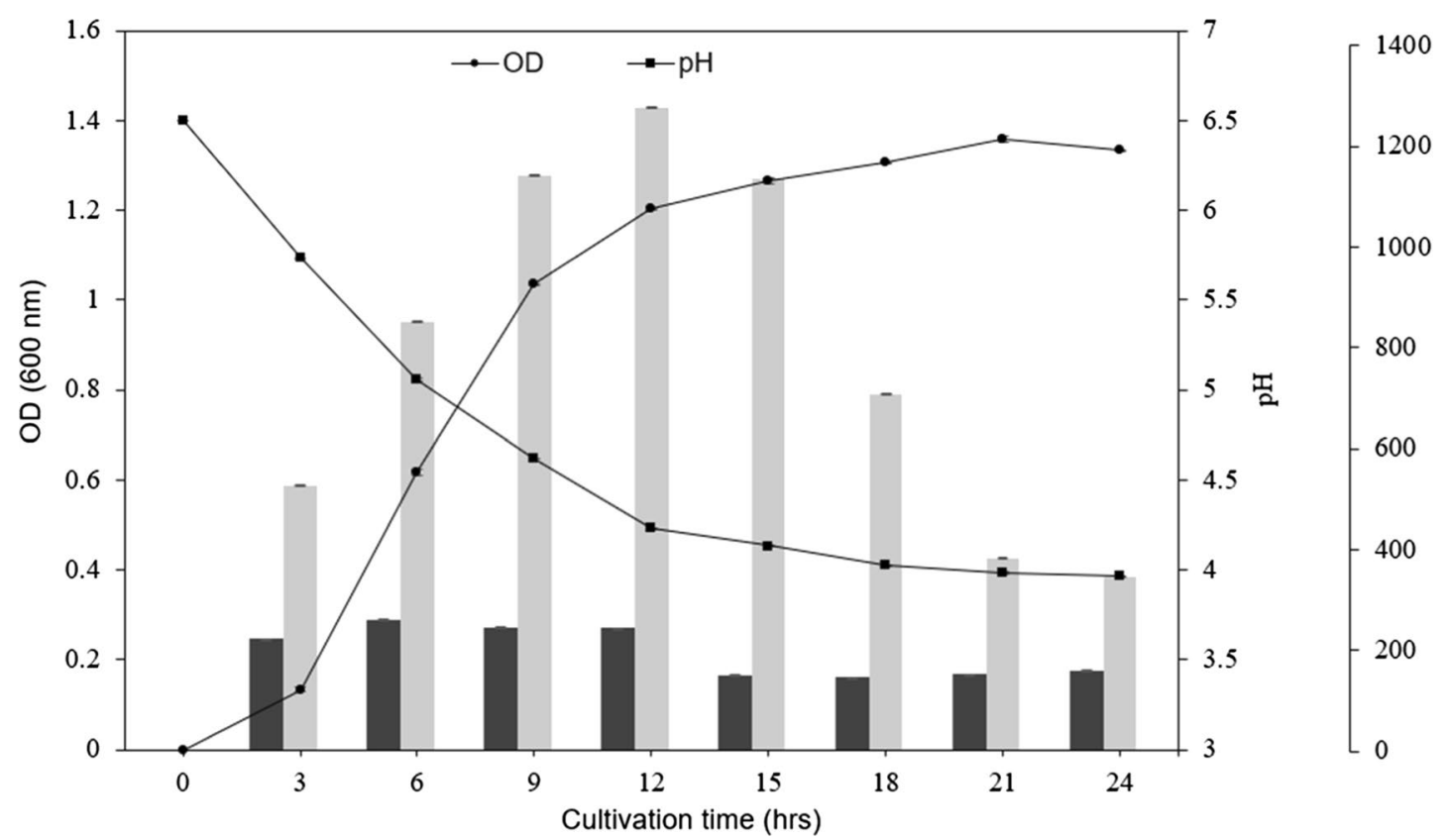

Fig. 3 Optical density $(\mathbf{O}), \mathrm{pH}(\boldsymbol{\square})$ and accumulation of hydrogen peroxide of L. gasseri HHuMIN D (light gray) and W. cibaria (dark gray) cultivated in MRS medium (pH6.5) at $37^{\circ} \mathrm{C}$ under anaerobic conditions $(n=3)$

Table 3 Susceptibility of L. gasserie HHuMIN D culture supernatant antimicrobial activity to various hydrolytic enzymes

\begin{tabular}{ll}
\hline Enzyme & Activity \\
\hline Control (no-enzyme) & +++ \\
Proteinase K & - \\
Trypsin & - \\
a-Chymotrypsin & - \\
Pepsin & +++ \\
a-Amylase & +++ \\
\hline
\end{tabular}

Fusobacterium nucleatum, Porphyromonas gingivalis, Prevotella intermedia, and Porphyromonas catoniae were used as indicators. Degree of growth inhibition by OD (600 nm): "+++", value similar to control; " ++ ", value weaker than control; "-", no growth. Culture supernatant was mixed with enzyme solutions at a final concentration of $1 \mathrm{mg} / \mathrm{ml}$

thiocyanate to oxygen-supplied cultures revealed that S. mutans was inhibited, but did not affect the growth of, S. sanguis and S. oralis [55]. Additional research contends that $\mathrm{H}_{2} \mathrm{O}_{2}$ produced by beneficial bacteria can decrease halitosis by inhibiting the growth of F. nucleatum and reducing the VSC produced by oral anaerobic bacteria [56].

L. gasseri HHuMIN D was shown to produce good amounts of hydrogen peroxide and is predicted to suppress harmful anaerobic bacteria that are vulnerable to hydrogen peroxide by continuous production. Further experimentation will be necessary to specifically investigate the effect of $L$. gasseri HHuMIN D's $\mathrm{H}_{2} \mathrm{O}_{2}$ on oral anaerobic bacteria.

\section{Susceptibility of the bacteriocin produced by L. gasserie HHuMIN D to hydrolytic enzymes}

Antibacterial activity was completely lost by proteinase $\mathrm{K}$, trypsin, and $\alpha$-chymotrypsin treatment, indicating that the antibacterial substance produced by L. gasseri HHuMIN D is proteinaceous, and possibly bacteriocin (Table 3 ). The fact that the activity was not lost by pepsin treatment is possibly an enzyme concentration issue or indicative of the lack of a specific cleavage site for pepsin to react at. Since $\alpha$-amylase did not affect the antibacterial activity, the carbohydrate moiety was either not present in the antibacterial molecule or not related to the antibacterial activity. Bacteriocins in which antibacterial activity is lost only with proteolytic enzyme treatment have previously been reported, as in the case of Bacillus licheniformis [27]. The greatest advantage of bacteriocin is that it is composed of proteins or peptides and it is decomposed by proteolytic enzymes in the digestive tract of the human body, so it is considered to be non-toxic and non-persistent [57-60]. 
Table 4 Coaggregation reactions between $W$. cibaria or $L$. gasseri HHUMIN D and various periodontal bacteria

\begin{tabular}{lrl}
\hline Strains & \multicolumn{2}{c}{ Coaggregation (\%) } \\
\cline { 2 - 3 } & W. cibaria & L.gasseri HHUMIN D \\
\hline Fusobacterium nucleatum KCOM 1001 & $4 \pm 2^{\text {a }}$ & $2 \pm 2^{\text {a }}$ \\
Porphyromonas gingivalis KCOM 2796 & $0 \pm 1^{\text {a }}$ & $0^{\text {a }}$ \\
Prevotella intermedia KCOM 2889 & $0 \pm 2^{\text {a }}$ & $28 \pm 5^{\text {b }}$ \\
Porphyromonas catoniae KCOM3169 & $0 \pm 1^{\text {a }}$ & $70 \pm 0^{\text {c }}$ \\
Streptococcus sobrinus KCOM1157 & $20 \pm 1^{\text {b }}$ & $37 \pm 2^{\text {b }}$ \\
Streptococcus mitis KCOM 1356 & $2 \pm 0^{\text {a }}$ & $46 \pm 3^{\text {d }}$ \\
Streptococcus oralis KCOM 1493 & $0 \pm 1^{\text {a }}$ & $30 \pm 2^{\text {b }}$ \\
Streptococcus gordonii KCOM 1788 & $11 \pm 6^{\text {b }}$ & $62 \pm 1^{\text {c }}$ \\
Streptococcus sanguinis KCOM 2167 & $50 \pm 3^{\text {c }}$ & $74 \pm 2^{\text {e }}$ \\
Streptococcus parasanguinis KCOM 2522 & $0 \pm 3^{\text {a }}$ & $6 \pm 3^{\text {a }}$ \\
Streptococcus mutans KCTC3065 & $29 \pm 4^{\text {d }}$ & $49 \pm 4^{\text {d }}$
\end{tabular}

Values are expressed as the mean \pm standard deviation. Means not sharing a common letter are significantly different groups at $p<0.001(\mathrm{n}=3)$

\section{Coaggregation of L. gasserie HHuMIN D and oral microorganisms}

L. gasseri HHuMIN D was shown to have the highest cohesion with $P$. catoniae (70\%) and P. intermedia $(28 \pm 5 \%)$ and there was no cohesion with $P$. gingivalis or F. nucleatum. Amongst aerobic oral bacteria, L. gasseri HHuMIN D coaggregated with S. sanguinis best (74 $\pm 2 \%)$, followed by S. gordonii (62 $\pm 1 \%)$, S. mutans (49 $\pm 4 \%)$, S. mitis ( $46 \pm 3 \%)$, S. sobrinus (37 $\pm 2 \%)$, S. oralis $(30 \pm 2 \%)$, and $S$. parasanguinis $(6 \pm 3 \%)$. However, the coaggregation of $W$. cibaria was relatively weaker than that of L. gasseri HHuMIN D (Table 4). L. gasseri HHuMIN D generally has higher coaggregation with oral facultative anaerobic bacteria than oral anaerobic bacteria with the exception of $P$. catoniae, which indicates that L. gasseri HHuMIN D possesses effective inhibitory capacity against oral facultative anaerobic bacteria. In another study evaluating the accumulation of 4 strains of human streptococci and 6 strains of lactobacillus used in consumer products, all probiotic strains showed the ability to aggregate with oral pathogens, but the degree of aggregation was different for each strain and dependent on time [61]. This indicates that only some Lactobacillus strains can aggregate with harmful bacteria.

Over 500 bacterial species have been identified in the oral cavity, of which 15-20 are known to produce toxic materials and are directly implicated in the evolution of various forms of periodontal disease [62]. Many of these harmful bacteria are also highly capable of coagulating with other microorganisms, live in the oral cavity and create toxic substances constantly, thus harming oral health [63]. Although the mechanism of aggregation has not been identified, the ability of probiotics to coaggregate with harmful bacteria is important as a secondary function to support the main function of probiotics. Oral probiotics must adhere well with harmful oral bacteria, inhibit their growth, and effectively diminish oral disease [64, 65]. Additionally, harmful bacteria are exposed directly to antimicrobials such as bacteriocins, lactic acid, and hydrogen peroxide through direct coaggregation with beneficial bacteria [66]. L. gasseri HHuMIN D's ability to coaggregate with harmful bacteria is therefore an important indicator of its potential value as an oral probiotic.

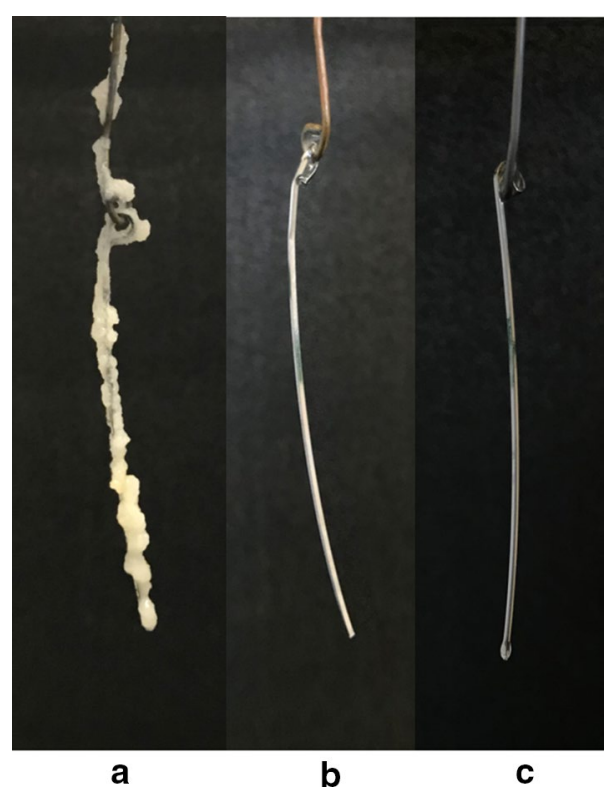

Fig. 4 Effect of L. gasseri HHuMIN D on the formation of artificial plaque by S. mutans on wires using BHI media containing 5\% sucrose. Artificial plaque formed on wires in S. mutans single culture (a), L. gasseri HHuMIN D single culture (b) and L. gasseri HHuMIN D / S. mutans co-culture culture $(\mathbf{c})$ are shown

Table 5 Effect of L. gasseri HHuMIN D on the formation of artificial plaque by Streptococcus mutans on wires using $\mathrm{BH}$ media containing $5 \%$ sucrose

\begin{tabular}{ll}
\hline Tested bacterial strain & Plaque weight $(\mathrm{mg})$ \\
\hline S. mutans & $105 \pm 5^{\mathrm{a}}$ \\
W. cibaria & $0 \pm 0^{\mathrm{b}}$ \\
L. gasseri HHuMIN D & $0 \pm 0^{\mathrm{b}}$ \\
W. cibaria + S. mutans & $53.4 \pm 12^{\mathrm{c}}$ \\
L. gasseri HHuMIN D + S. mutans & $0 \pm 0^{\mathrm{b}}$ \\
\hline
\end{tabular}

The values are expressed as the mean \pm standard deviation. Means not sharing a common letter are significantly different groups at $p<0.001(\mathrm{n}=3)$ 
Effect of L. gasseri HHuMIN D on the formation of artificial dental plaque by $S$. mutans

Artificial dental plaques formed on calibration wire suspended in $S$. mutans inoculated broths, but such plaques were not developed in L. gasseri HHuMIN D and $W$. cibaria inoculated broths. No artificial dental plaque was formed on calibration wire in broth co-cultured with $S$. mutans and L. gasseri HHuMIN D, indicating 100\% inhibition (Fig. 4; Table 5).

In one study, $S$. mutans created artificial dental plaque was suppressed by $53 \%$ by E. faecium T7 co-culture [29]. In another experiment, Lactobacillus lactis 1370 suppressed plaque formation by 95\% [67]. Compared to other organisms tested, L. gasseri HHuMIN D strongly inhibits dental plaque formation by $S$. mutans.

\section{Adhesion of L. gasseri HHuMIN D}

Oral epithelial cell monolayer testing is a method used to identify beneficial bacteria and has also been used as a guide to test the attachment of beneficial bacteria to the oral epithelium. According to an earlier study, if the

Table 6 Adhesion ability to KB cells of tested strains

\begin{tabular}{lc}
\hline Strains & No. of CFU recovered \\
\hline L. gasseri HHUMIN D & $4.41 \pm 1.4^{\mathrm{a}}$ \\
F. nucleatum KCOM1001 & $18.35 \pm 4.0^{\mathrm{b}}$ \\
S. mutans KCTC3065 & $2.57 \pm 0.1^{\mathrm{a}}$ \\
\hline
\end{tabular}

The values are expressed as the mean \pm standard deviation for triplicate samples of lysates from the infection of $10^{5} \mathrm{~KB}$ cells by $10^{8}$ bacteria. Means not sharing a common letter are significantly different groups at $p<0.01(n=3)$ number of attached bacteria per $\mathrm{KB}$ cell is 1.5 or more, the attachment capacity is considered to be very strong and if the number of attached bacteria is 1.5 to 1 , the adhesion capacity is considered to be strong. If the number of bacteria attached is 1 to 0.5 , the ability to adhere is moderate and if the number of the bacteria attached is less than 0.5 , the ability to adhere is considered weak [68]. The KB cell adhesion ability of L. gasseri HHuMIN D was determined to be $4.41 \pm 1.4$ cells per cell- very strong. F. nucleatum showed a very high adhesion capacity of $18.35 \pm 4.0$, and $S$. mutans showed a strong adhesion capacity of $2.57 \pm 0.1$ (Table 6). Strains with strong adhesion are likely to adhere to oral epithelial cells, form colonies, and inhibit the attachment of pathogenic bacteria to epithelial cells. In a previous analysis, the adhesion abilities of harmful bacteria were measured for $P$. intermedia from $4.110^{4} \pm 2.710^{4}$ to $152 \pm 57$ per $10^{5} \mathrm{~KB}$ cells, for $P$. gingivalis at $9.610^{5} \pm 1.010^{5}$, and for $E$. coli at $278 \pm 133$ [68]. In another study, F. nucleatum's KB cell adhesion at the initial dose was from $19.2 \pm 0.3 \%$ to $1.5 \pm 0.4$, suggesting that $F$. nucleatum has very strong adhesion capabilities [69].

The ability of L. gasseri HHuMIN D to inhibit cell adhesion by harmful bacteria was assessed by conducting protection and displacement assays. In the protection assays, L. gasseri HHuMIN D was allowed to bind to KB cells before introducing harmful oral bacteria. L. gasseri HHuMIN D reduced the adhesion of $F$. nucleatum and $S$. mutans to cells by $100 \%$ and $90 \%$, respectively. Unfortunately, L. gasseri HHuMIN D's cell adhesion was reduced by $63 \%$ and $71 \%$, respectively, by competition with $F$.

Table 7 The number of experimental bacteria and pathogens bound to KB cells in adhesion ability, protection assays and displacement assays

\begin{tabular}{|c|c|c|c|}
\hline & Strains & $\begin{array}{l}\text { No. of CFU recovered } \\
\mathrm{a}\left(\times 10^{5}\right)\end{array}$ & $\begin{array}{l}\text { Adhesion } \\
\text { inhibitory rate } \\
(\%)\end{array}$ \\
\hline \multirow[t]{3}{*}{ Positive Control } & L. gasseri HHuMIN D & $4.41 \pm 1.4$ & \\
\hline & F. nucleatum KCOM1001 & $18.35 \pm 4.0$ & \\
\hline & S. mutans KCTC3065 & $2.57 \pm 0.1$ & \\
\hline \multirow[t]{4}{*}{ Protection assays ${ }^{b}$} & (L.gasseri HHuMIN D $\rightarrow$ F. nucleatum KCOM1001) L. gasseri HHuMIN D & $1.64 \pm 0.2^{* *}$ & 63 \\
\hline & (L. gasseri HHuMIN D $\rightarrow$ F. nucleatum KCOM1001) F. nucleatum KCOM1001 & $0.05 \pm 0.0^{* * *}$ & 100 \\
\hline & (L. gasseri HHuMIN D $\rightarrow$ S. mutans KCTC3065) L. gasseri HHuMIN D & $1.27 \pm 0.6^{* *}$ & 71 \\
\hline & (L. gasseri HHuMIN D $\rightarrow$ S. mutans KCTC3065) S. mutans KCTC3065 & $0.25 \pm 0.2^{* * *}$ & 90 \\
\hline \multirow[t]{4}{*}{ Displacement assays ${ }^{c}$} & (F. nucleatum KCOM1001 $\rightarrow$ L. gasseri HHuMIN D) L. gasseri HHuMIN D & $1.32 \pm 0.4^{* *}$ & 70 \\
\hline & (F. nucleatum KCOM1001 $\rightarrow$ L. gasseri HHuMIN D) F. nucleatum KCOM1001 & $2.10 \pm 0.8^{* * *}$ & 89 \\
\hline & (S. mutans KCTC3065 $\rightarrow$ L. gasseri HHuMIN D) L. gasseri HHuMIN D & $1.18 \pm 0.3^{* *}$ & 73 \\
\hline & (S. mutans KCTC3065 $\rightarrow$ L. gasseri HHuMIN D) S. mutans KCTC3065 & $0.27 \pm 0.1^{* * * *}$ & 90 \\
\hline
\end{tabular}

\footnotetext{
${ }^{a}$ Values represent the means \pm the standard deviations for triplicate samples of lysates from the infection of $10^{5} \mathrm{~KB}$ cells by $10^{8}$ bacteria. Compared with the positive control group: ${ }^{*} p<0.05,{ }^{* *} p<0.01,{ }^{* * *} p<0.001,{ }^{* * *} p<0.0001(\mathrm{n}=3)$

b Protection assays are a method of investigating how harmful bacteria are inhibited from attaching by selected bacteria which are already attached

c Displacement assays are a method of investigating the degree of attachment by selected bacteria after harmful bacteria are already attached
} 
nucleatum and S. mutans. L. gasseri HHuMIN D strongly inhibited F. nucleatum adhesion and it appears that the cell adhesion of L. gasseri HHuMIN D might also have been reduced by competition with harmful oral bacteria (Table 7).

The attachment of L. gasseri HHuMIN D after the attachment of harmful oral bacteria was measured in displacement assays. With $F$. nucleatum and S. mutans, the cell adhesion of L. gasseri HHuMIN D decreased to 70 and $73 \%$, respectively. However, the attachment of harmful oral bacteria decreased by 89 and $90 \%$, respectively. Taken together, these two results indicate a stronger ability to inhibit the binding of harmful bacteria when first bound to L. gasseri HHuMIN D. This suggests that $L$. gasseri HHuMIN D is more effective in preventing than inhibiting the attachment of harmful oral bacteria. Consequently, continuous intake is likely necessary to enable adhesion of L. gasseri HHuMIN D to highly concentrated oral cavity cells. Other researchers have theorized there is competition for common adhesion receptors between harmful bacteria and beneficial oral bacteria [70] and that antibacterial or antiadhesive factors produced by beneficial bacteria inhibit harmful oral bacteria from adhering after beneficial bacteria aggregate [71].

\section{Safety evaluations of $L$. gasseri HHuMIN D}

Microorganisms may create various poisonous substances by nitrogen derivatives through protein, peptide and amino acid decomposition in saliva or food [73]. When a microorganism enters the large intestine, it is able to generate poisonous substances such as phenol, ammonia and indole by decomposition of proteins [72]. Ammonia formed by microorganisms is known to migrate to the liver and cause cell damage cofactors and chronic hepatic damage. The production of ammonia from microorganisms is closely related to human health and must be assessed to demonstrate the safety of commercial probiotics. According to Vince and Burridge [73], Clostridia, Enterobacter, Bacillus spp., and Gramnegative anaerobes create large amounts of ammonia. Furthermore, certain Streptococci, Micrococci, and Grampositive non-spore forming anaerobes release small quantities of ammonia, and Gram-positive aerobic rods generate trace amounts of ammonia. Certain strains of Lactobacillus can produce small amounts of ammonia during growth. The evaluation of ammonia production confirmed the safety of L. gasseri HHuMIN D; it produced no ammonia. In contrast, Enterococcus faecium ATCC19433, a positive control, produced $109 \pm 7 \mu \mathrm{g} / \mathrm{mL}$ of ammonia. L. gasseri HHuMIN D's ammonia production is below the level of concern in South Korea's Ministry of Food and Drug Safety's milk product quality [23].
Biogenic amines (BAs) derived from amino acids are common anti-nutritional compounds in animals and humans. Ingestion of massive amounts of BAs may cause symptoms similar to significant allergic reactions. BAs have been identified as causative agents in many cases of food poisoning and are critical from a hygienic point of view because they can induce a variety of pharmacological reactions [74]. BAs are involved in numerous mammalian metabolic and intracellular processes, such as synaptic transmission, modulation of blood pressure, allergic reactions, and management of cellular growth. Probiotic bacteria, commonly used in the food industry, produce BAs through microbial metabolic activities such as decarboxylation and protein molecule transamination [75]. L. gasseri HHuMIN D did not produce cadaverine, histamine, putrescine, or tyramine. Since ammonia and/or BAs are used as a quality indicator for fermented foods, L. gasseri HHuMIN D's absence of ammonia and BA activity suggests that $L$. gasseri HHuMIN D is suitable for use in the manufacture of fermented and nonfermented foods.

The Guidelines for the Evaluation of Probiotics in Food, produced by FAO and WHO joint research, states, "If the strain under evaluation belongs to a species with known hemolytic potential, determination of hemolytic activity is required" $[24,76]$. The hemolytic characteristics of microorganisms are an important measurement criterion for the safety of bacteria since they may liquefy/ degrade red blood cells and ultimately cause anemia and edema. Among probiotics, Lactobacillus spp. are graded as $\alpha$-hemolytic microorganisms [77]. However, several Lactobacillus spp. (L. sakei MBSa1 bac + , L. curvatus MBSa3 bac + and L. lactis 368 bac-) demonstrate strong $\beta$-hemolysis [78]. L. ivanovii developed $\beta$-hemolysis colorless zones around colonies in BL agar added 5\% sheep blood but L. gasseri HHuMIN D cultivated in the same medium did not reveal colorless zones around the colonies (Fig. 5). Therefore, L. gasseri HHuMIN D does not cause hemolysis.

While there is no need for a safety assessment for mucin deterioration in the oral cavity, this study was performed to take into consideration the potential for ingestion and entry to the intestine by $L$. gasseri HHuMIN D. L. gasseri HHuMIN D was also assessed for the potential of translocation by in vitro mucolytic assays. Several research teams have studied the mucous dissolving capacities of human pathogenic bacteria since 1980, and that is now considered a measure of microbial virulence and microbial toxicity [79-82]. The intestinal mucus gel coating is a membrane made of glycoproteins and is an essential part of the intestine. Bacterial translocation is considered one of the most critical probiotic safety tests due to the risk for septicemia and bacteremia 

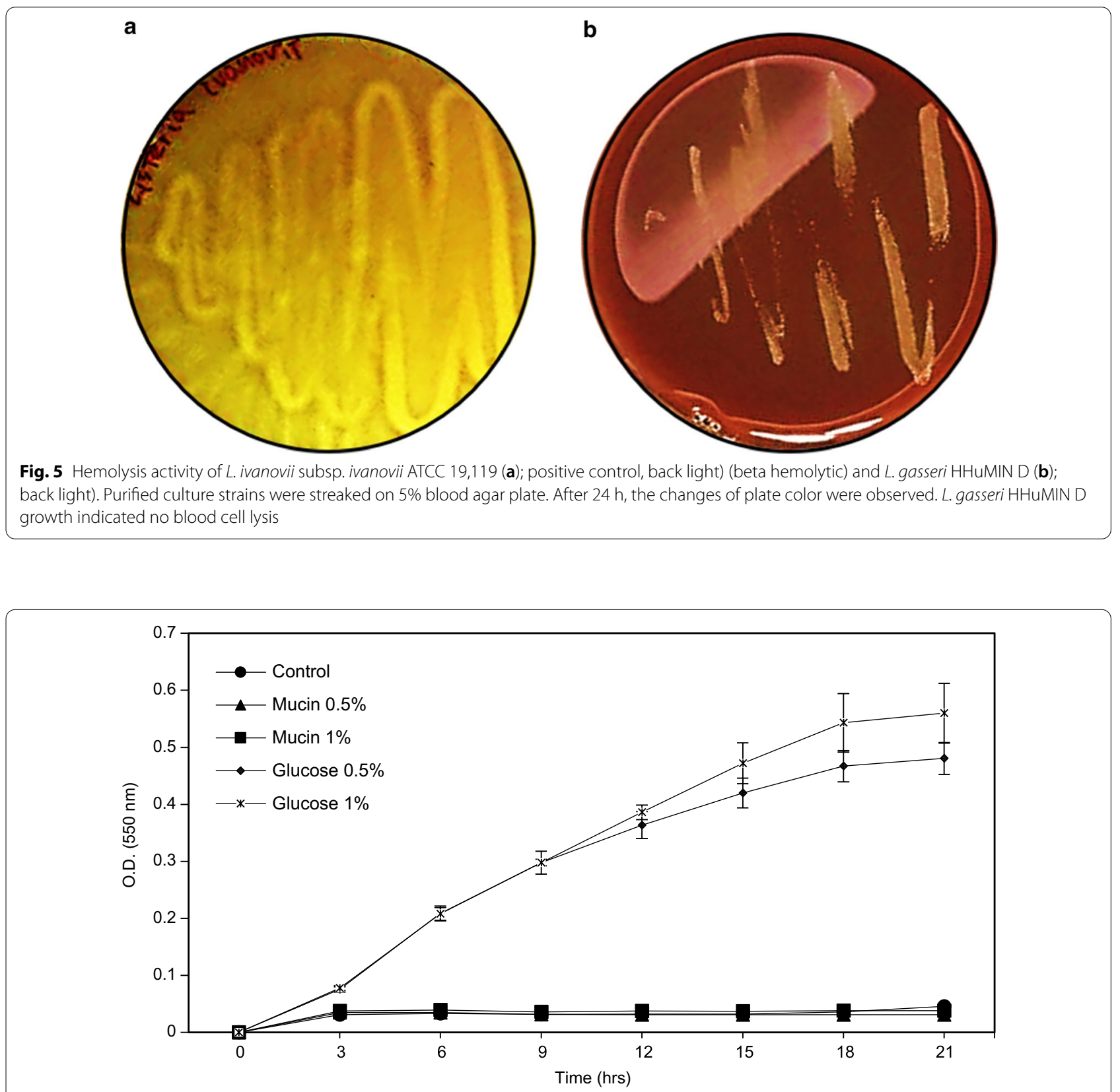

Fig. 6 The effect of different concentrations $(0,0.5$ and $1 \%[\mathrm{w} / \mathrm{V}])$ of mucin and dextrose on L. gasseri HHuMIN D in modified MRS, evaluated by optical density $(550 \mathrm{~nm})$ and recorded after 3 to $21 \mathrm{~h}(\mathrm{n}=3)$

endocarditis [83]. Although most microorganisms do not exhibit mucolytic activity, several studies have reported that certain microorganisms do and the genes that induce mucin degradation enzymes have been identified [84]. Various intestinal pathogens are known to hydrolyze glycoprotein-based mucus gel layers and possess the ability to metabolize mucus-derived monosaccharides [85].

If $L$. gasseri HHuMIN D had the ability to produce mucinases, through mucin degradation it would be able to survive and grow aggressively in the presence of mucin and no other carbohydrate sources. As illustrated in Fig. 6, L. gasseri HHuMIN D growth was actively induced by the addition of glucose as the carbon source. But growth was not observed when glucose was replace by mucin. These results show that L. gasseri HHuMIN D does not use mucin as a carbon source for growth.

To distinguish antibiotic tolerance from antibiotic-sensitivity, microbiological cut-off values for the antibiotic 
tolerance of microorganisms used as food were defined by the European Food Safety Authority [86]. In a study of Lactobacillus spp.s susceptibility to 23 antibiotics, some lactobacilli showed resistance to kanamycin, vancomycin, and chloramphenicol. The authors hypothesized that strains with these genes did not necessarily indicate cause for concern about the transition of antibiotic resistance and could be used in food and medicinal formulations as natural biopreservatives [87]. Ampicillin, erythromycin, vancomycin, chloramphenicol, and clindamycin were low compared to the cut-off values proposed by EFSA. Antibiotic resistance can be transmitted via plasmids, the assessment of antibiotic resistance is a significant criterion for assessing Lactobacillus sp. safety [88]. Therefore, we used WGS to genetically identify the antibiotic resistance gene of L. gasseri HHuMIN D and ascertain the possibility of transmission to other bacteria through the presence or absence of a plasmid. Except for gentamicin, streptomycin, and kanamycin, the MIC values of $L$. gasseri HHuMIN D were less than or equal to the cut-off values proposed by the EFSA. As shown in Table 8, L. gasseri HHuMIN D was sensitive to ampicillin, carbenicllin, cephalothin, chloramphenicol, clindamycin, dicloxacillin sodium salt hydrate, erythromycin, lincomycin, methicillin, penicillin $G$, tetracycline, and vancomycin (MICs ranged from 0.01 to $4 \mu \mathrm{g} / \mathrm{mL}$ ). There was general resistance to bacitracin, gentamicin, katamycin, metronidazole, neomycin, polymyxin B, phosphomycin, streptomycin, and trimethoprim-Sulfamethoxazole (all MICs were greater than $32 \mu \mathrm{g} / \mathrm{mL}$ ).

Table 8 Antimicrobial susceptibility (MIC values) of L. gasseri HHuMIN D

\begin{tabular}{|c|c|c|c|c|c|}
\hline \multirow[t]{3}{*}{ Classification } & \multirow[t]{3}{*}{ Antimicrobial agent } & \multicolumn{4}{|l|}{ (MIC values, $\mu \mathrm{g} / \mathrm{mL}$ ) } \\
\hline & & \multicolumn{2}{|c|}{ Cut-off of Lactobacillus (EFSA ${ }^{a}$ ) } & \multicolumn{2}{|l|}{ Strain } \\
\hline & & $\begin{array}{l}\text { Lactobacillus obligate } \\
\text { homofermenta tive }^{b}\end{array}$ & $\begin{array}{l}\text { Lactobacillus obligate } \\
\text { heterofermentative }^{c}\end{array}$ & L. gasseri HHuMIN D & $\begin{array}{l}\text { E. faecium } \\
\text { ATCC } \\
29,212\end{array}$ \\
\hline \multirow[t]{5}{*}{$\beta$-Lactam group } & Penicillin G & & & 0.063 & 0.5 \\
\hline & Carbenicllin (disodium salt) & & & 0.5 & 8 \\
\hline & Methicillin & & & 2 & 16 \\
\hline & Ampicillin (sodium salt) & 1 & 2 & 0.25 & 0.25 \\
\hline & Dicloxacillin sodium salt hydrate & & & 0.5 & 4 \\
\hline \multirow[t]{4}{*}{ Aminoglycoside group } & Gentamicin (sulfate) & 16 & 16 & 32 & 256 \\
\hline & Streptomycin (sulfate salt) & 16 & 64 & 64 & $>256$ \\
\hline & Kanamycin (sulfate) & 16 & 32 & 512 & 256 \\
\hline & Neomycin (sulfate) & & & 256 & 1024 \\
\hline Cephem group & Cephalothin (sodium salt) & & & 1 & 16 \\
\hline Tetracycline group & Tetracycline & 4 & 4 & 4 & 32 \\
\hline \multirow[t]{2}{*}{ Peptide group } & Polymyxin B (sulfate salt) & & & $>1024$ & $>1024$ \\
\hline & Bacitracin & & & 64 & \\
\hline Macrolide group & Erythromycin & 1 & 1 & 0.5 & 8 \\
\hline Synthetic antimicrobial group & Metronidazole & & & $>256$ & $>256$ \\
\hline \multirow[t]{8}{*}{ The other group } & Vancomycin $(\mathrm{HCl})$ & $2^{d}$ & n.r & 0.5 & 2 \\
\hline & Chloramphenicol & 4 & 4 & 2 & 8 \\
\hline & Lincomycin (hydrochloride) & & & 4 & \\
\hline & Rifampicin & & & $<0.125$ & 0.5 \\
\hline & Clindamycin (hydrochloride) & 1 & 1 & 0.5 & $>16$ \\
\hline & Phosphomycin (disodium salt) & & & $>1024$ & 32 \\
\hline & Mupirocin & & & 16 & 64 \\
\hline & $\begin{array}{l}\text { Trimethoprim-Sulfamethoxazole } \\
\text { (Co-trimoxazole) }\end{array}$ & & & $>256$ & 32 \\
\hline
\end{tabular}

n.r. not required.

a Data from EFSA (2012)

b including L. delbrueckii, L. helveticus, L. gasseri

c including L. fermentum

${ }^{d}$ not required for L. salivarius 


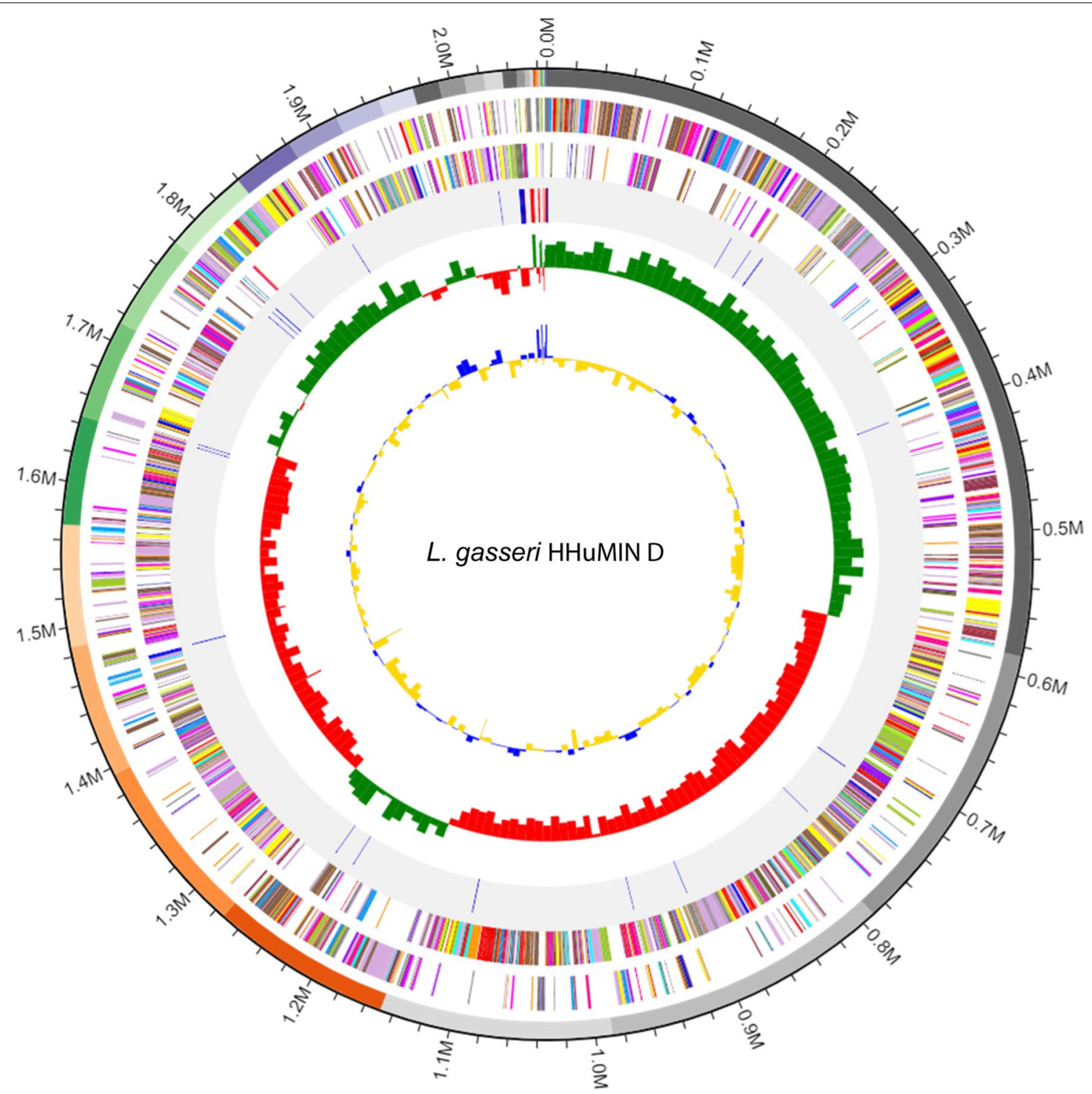

Fig. 7 Genome map of L. gasseri HHuMIN D. Whole genome sequencing of L. gasseri HHuMIN D was performed by Chunlab, Inc. (Seoul, Korea), which used PacBio Sequel Systems (Pacific Biosciences, Menlo Park, CA, USA) and analyzed using CLgenomics ${ }^{\mathrm{TM}}$ and EZBioCloud Apps programs (Chunlab, Seoul, Korea). The gene content circular image consists of five circles, and each circle shows the information of rRNA/tRNA, Reverse CDS, Forward CDS, GC Ratio and GC skew from the outside to the inside

Whole genome sequencing (WGS) is a technique which studies the functional aspects of a microorganism by sequencing a microorganism's entire genome and comparing it to a gene previously identified [89]. The size of the entire gene sequence of L. gasseri HHuMIN D was 2,066,663 bp and the GC composition ratio was $34.9 \%$. The average GC content of Lactobacillus spp. is $46.61 \%$, L. gasseri HHuMIN D is lower than the average GC content of Lactobacillus spp. The number of rRNA genes and tRNA genes were 7 and 63, respectively. The number of coding sequences (CDSs) was 2,015, and the average of the coding sequence length was $923.9 \mathrm{bp}$. Figures 7 and 8 show a genetic map of L. gasseri HHuMIN D and a functional classification based on COG.

Bacteriocin is a proteinaceous bacterial product with bactericidal activity [90]. Any Gram-positive bacteria that produce bacteriocin are considered to be active against Gram-negative bacteria [91]. This broad spectrum of compounds is important in preventing the growth of harmful bacteria and alleviating disease. They 


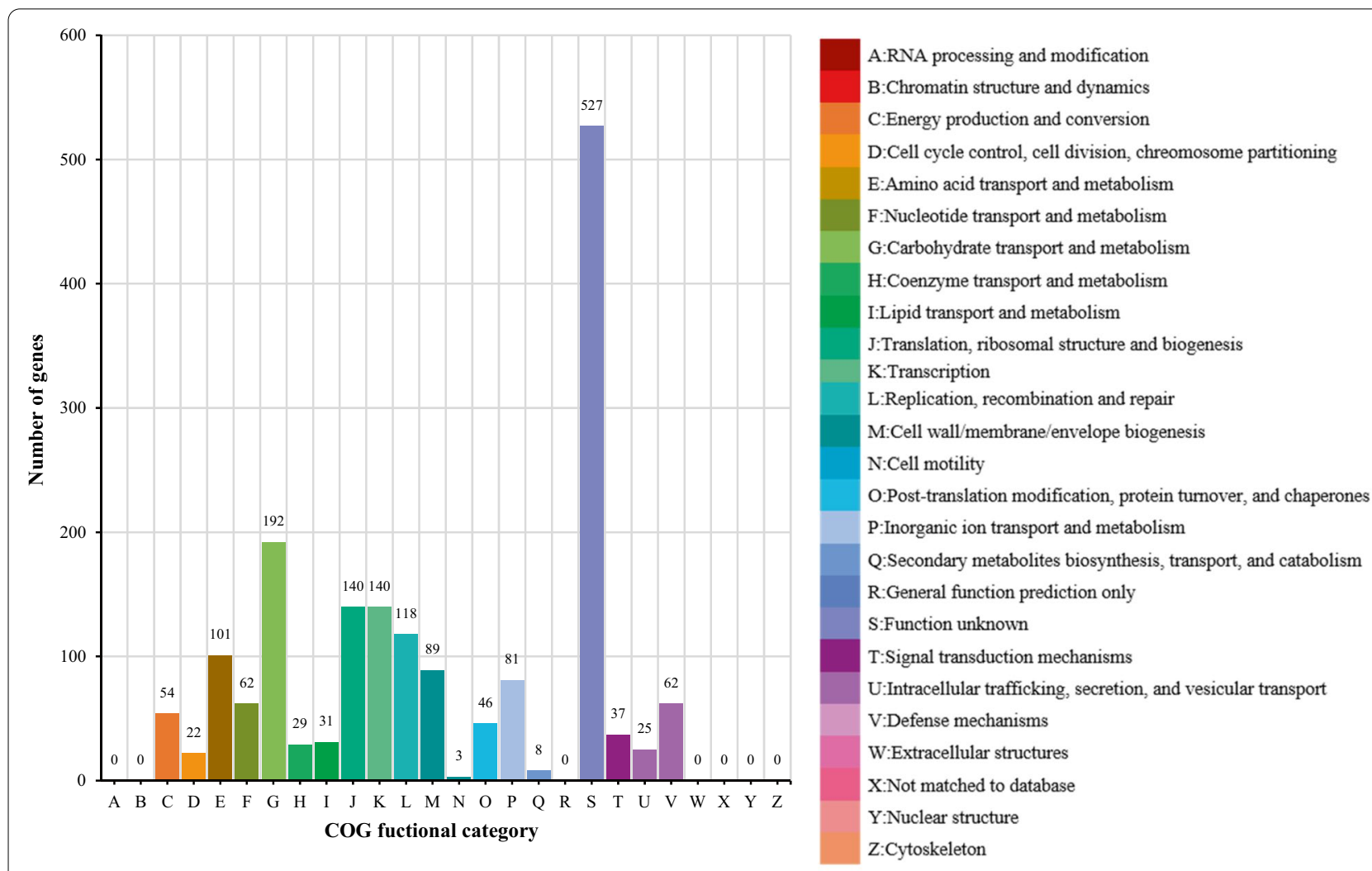

Fig. 8 Functional categories based on EggNog/COG of genome of L. gasseri HHuMIN D. Whole genome sequencing of L. gasseri HHuMIN D was performed by Chunlab, Inc. (Seoul, Korea), which used PacBio Sequel Systems (Pacific Biosciences, Menlo Park, CA, USA) and analyzed using $\mathrm{CLgenomics}^{\mathrm{TM}}$ and EZBioCloud Apps programs (Chunlab, Seoul, Korea). The function of each protein was found through homology comparison with NCBI's RefSeq Database, and functional categories were completed by synthesizing information such as COG classification by NCBI COG, SEED classification by FIGfam, and EC classification etc. The figure is a combination of the assignments of each COG and the functional category ( 25 categories, which are often designated from A to Z) using EggNog

are produced by specific lactic acid bacteria, including lactococci, lactobacilli, and pediococci [92].

Since 1980, the L. acidophilus group has been classified by DNA-DNA homology into six homologous species: L. acidophilus, L. amylovorus, L. crispatus, $L$. gallinarum, L. gasseri and L. johnsonii [93, 94]. Out of these six species $L$. gasseri is thought to be the primary member inhabiting the human intestine, and studies on the bacteriocins produced by this bacterium have been conducted [94-96]. Lactacin F is the best-studied bacterocin in the LAB class IIb. Gassericin T is a 2-component bacteriocin consisting of GatA and GatX and of the lacticin-F family; it is known as the primary bacteriocin developed by L. gasseri strains [97]. Gassericin $\mathrm{T}$ is heat-stable $\left(121{ }^{\circ} \mathrm{C}, 10 \mathrm{~min}\right), \mathrm{pH}$-tolerant (pH 2-11) and bactericidal against several food poisoning gram-positive bacteria such as Bacillus cereus, Listeria monocytogenes, and Staphylococcus aureus [94]. Helveticin J was first studied in L. helveticus. Helveticin $J$ can be used as an indicator of closely related species, is active at neutral $\mathrm{pH}$ under aerobic or anaerobic conditions and is sensitive to proteases and heat $(30 \mathrm{~min}$ at

Table 9 Genes and genetic characteristics of L. gasseri HHuMIN D bacteriocin on the basis of whole genome sequencing results

\begin{tabular}{|c|c|c|c|c|}
\hline Gene & Length & Product & Database hit & Homology \\
\hline hlv & 996 & Bacteriocin helveticin-J & UniProtKB: P22294 & $\begin{array}{l}\text { L. paragasseri strain NCTC } 13,720 \text { (98.09\%), L. gasseri } \\
\text { strain EJL }(97.89 \%)\end{array}$ \\
\hline lafA & 228 & Bacteriocin lactacin-F subunit LafA & $\begin{array}{l}\text { UniProtKB: P24022 } \\
\text { NCBI: LJ_RS03150 }\end{array}$ & L. gasseri strain EJL (100\%), L. gasseri strain 151-2 (100\%) \\
\hline $\operatorname{laf} x$ & 198 & Bacteriocin lactacin-F subunit LafX & UniProtKB: Q48509 & L. gasseri strain EJL (100\%), L. gasseri strain 151-2 (100\%) \\
\hline
\end{tabular}


$100{ }^{\circ} \mathrm{C}$ ) [98]. These 2 bacteroicins are good candidate biopreservatives.

The whole genome sequence of $L$. gasseri HHuMIN D was verified through CLgenomicsTM and EZBioCloud applications to see if this strain qualifies for GRAS status. All results are summarized in Table 9. We found that the antimicrobial activity against oral harmful bacteria may be the result of one or more of three bacteriocin genes in which the antimicrobial activity of $L$. gasseri HHuMIN D was found: hlv, lafA, lafX. The helveticin J from L. gasseri HHuMIN D showed 98.09\% homology with helveticin from $L$. paragasseri strain NCTC13720, and $97.89 \%$ homology with helveticin from L. gasseri strain EJL. The lactacin-F (subunit

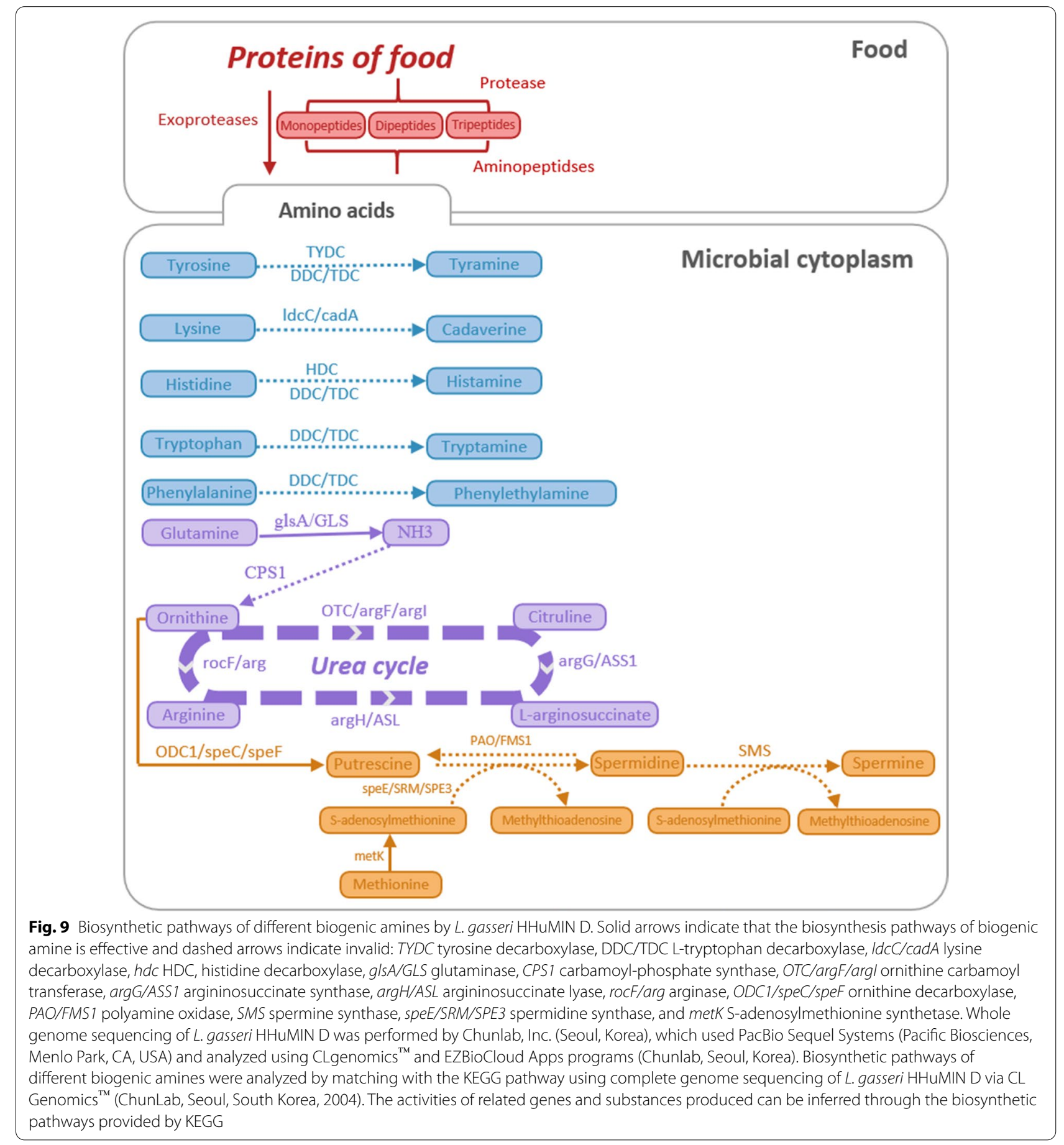


LafA and subunit LafX) from L. gasseri HHuMIN D showed $100 \%$ homology with lactacin-F from L. gasseri strain EJL and L. gasseri strain 151-2. The WGS cannot determine which of these genes are responsible for inhibitory activity against the pathogens tested and there is no data for reference because there are insufficient screening studies on bacteriocins produced by L. gasseri HHuMIN D against harmful oral bacteria. Further studies on bacteriocins produced by L. gasseri HHuMIN D and their effects on harmful oral bacteria are needed.

The whole genome sequence of $L$. gasseri HHuMIN D was scanned via the CLgenomicsTM and EZBioCloud applications for genes that generate enzymes engaged in the metabolic pathways that create biogenic amines. Figure 9 demonstrates the biosynthetic mechanism of different biogenic amines.

No genes were identified that produce tyrosine decarboxylase (which generates tyramine from tyrosine), L-tryptophan decarboxylase (which generates tyramine from tyrosine, histamine from histidine, tryptamine from tryptophan, and phenylethylamine from phenylalanine), lysine decarboxylase (which generates cadaverine from lysine), histidine decarboxylase (which generates histamine from histidine), carbamoyl-phosphate synthase (which generates ornithine from NH3), ornithine carbamoyl transferase (which generates citruline from ornithine), argininosuccinate synthase (which generates
L-arginosuccinate from citruline), argininosuccinate lyase (which generates arginine from L-arginosuccinate), arginase (which generates ornithine from arginine), polyamine oxidase (which generates putrescine from spermidine), spermine synthase (which generates spermine from spermidine), spermidine synthase (which generates methylthioadenosine from S-adenosylmethionine) (Fig. 9), and genes were identified that produce glutaminase (which generates NH3 from glutamine), ornithine decarboxylase (which generates putrescine from ornithine), S-adenosylmethionine synthetase (which generates S-adenosylmethionine from methionine) (Fig. 9).

Glutamine can be converted to NH3 through glsA or GLS and converted NH3 can be converted to ornithine through CPS1. As a result of confirming the mechanism, L. gasseri HHuMIN D can be converted from glutamine to NH3 via glsA or GLS but cannot be converted to ornithine since there is no CPS1 thereafter. If ornithine exists, it can be converted via the urea cycle into citriuline, L-arginosuccinate, and arginine; the associated genes have not been found in the L. gasseri HHuMIN D genome. Polyamines such as putrescine, spermidine and spermine are produced using ornithine as the starting substrates through different pathways (Fig. 9). Except for methionine adenosyltransferase (MAT) and putrescine biosynthetic genes (ODC1, speC, speF), no genes encoding polyamine biosynthetic enzymes were found in the L. gasseri HHuMIN D genome. Contrary to the genetic

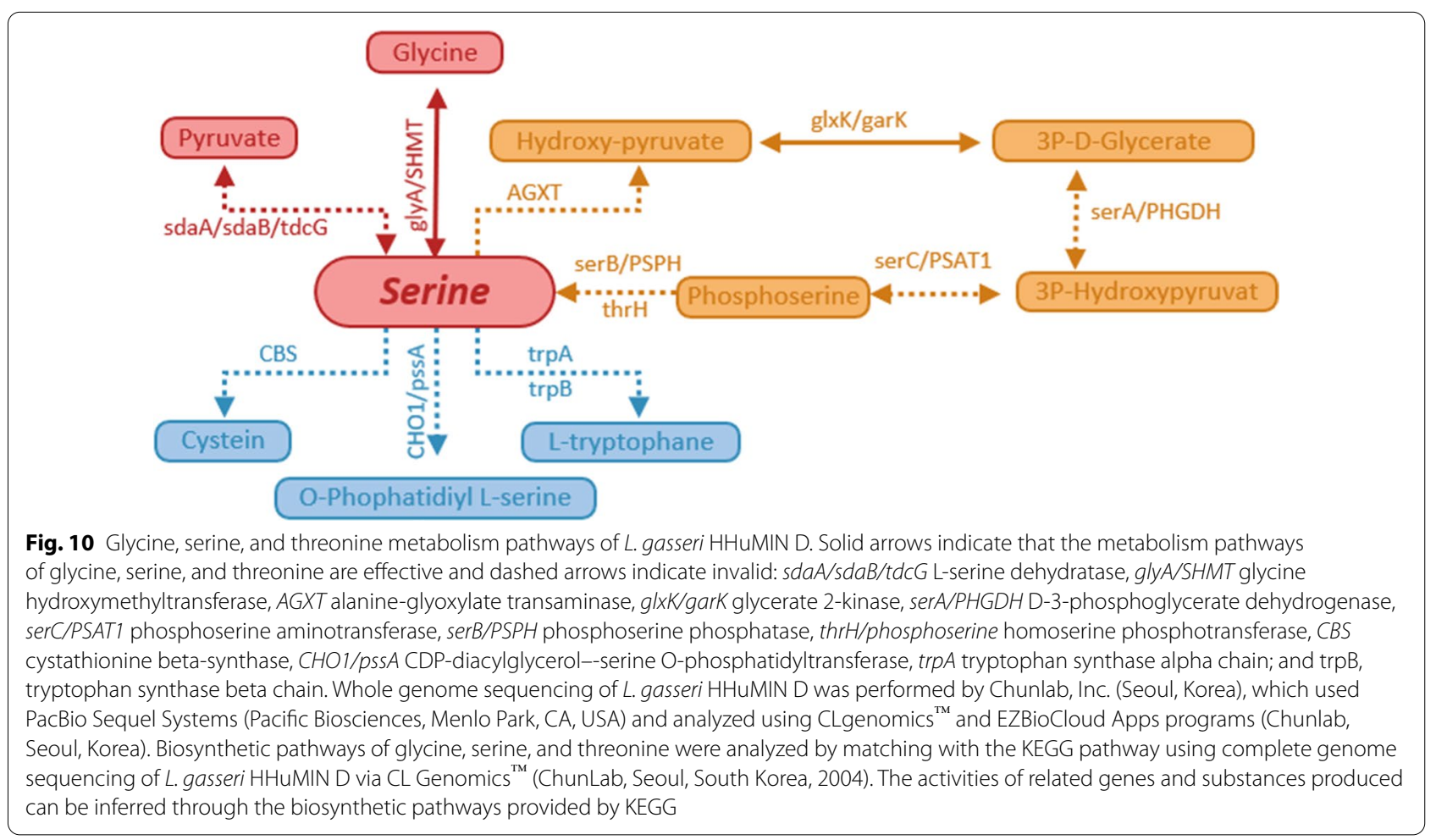


results, the production amount seems to be very small, as bioamines are not measured in BA production capacity evaluation.

Phosphatidylserine plays a crucial role in the development of blood clotting and thrombus, so the genes involved in the metabolic pathways that create this compound were evaluated. L. gasseri HHuMIN D does not have any genes that produce phosphatidylserine in the metabolic pathway (Fig. 10).

Virulence genes lend pathogenicity to microorganisms. L. gasseri HHuMIN D was assumed to be non-pathogenic using VirulenceFinder 2.0, a program that enables pathogenic and non-pathogenic bacteria to be differentiated using data from the whole genome sequence in order to classify potential virulence genes within the genome. The L. gasseri HHuMIN D genome sequence was compared with the genomic sequences of four noted pathogens (Escherichia coli, Enterococcus, Listeria, and Staphylococcus aureus). Virulence factors evaluated included Escherichia coli shiga toxin gene and Staphylococcus aureus exoenzyme genes, host immune alteration or evasion genes and toxin genes. The L. gasseri HHuMIN D genomic sequencing revealed no virulence factors or toxic or pathogenic genes.
L. gasseri HHuMIN D genes related to antibiotic resistance were discovered using the ideal and strict algorithms of CARD (Table 10). The genome of L. gasseri HHuMIN $\mathrm{D}$ was found to contain 16 putative genes associated with resistance to beta-lactams (7), bacitracin (1), aminoglycoside (1), aminocoumarin (1), lincomycin (1), polymyxin (1), macrolide (2) and multi antibiotic (2). Antibiotic resistance assays showed that $L$. gasseri HHuMIN D was resistant to gentamicin, streptomycin, and kanamycin, but genes associated with antibiotic resistance were not detected. Although penicillin, bacitracin, and lincomycin genes linked to resistance have been identified, the organism itself has demonstrated low resistance in antibiotic resistance assays. It must be noted that the L. gasseri HHuMIN D genome and the phenotype for antibiotic resistance do not match completely. It should be considered that the L. fermentum OK genome and the phenotypes of antibiotic resistance may not exactly fit. For DNA replication, GyrA is necessary. Multidrug efflux transporters are involved in several detoxifying activities in cells and are widely distributed across many forms of Lactobacillus spp. [89]. There are also safety factors regarding the use of antibiotic-resistant strains, due to the possibility of transferring antibiotic-resistance

Table 10 Putative antibiotic resistance genes in the L. gasseri HHuMIN D genome

\begin{tabular}{|c|c|c|c|c|c|c|}
\hline Gene ID & Name & Length & COG_name & KEGG_name & Product & Category \\
\hline HHuMIN D_00032 & GLIA & 1452 & 2814 & 22,134 & multidrug resistance protein & multi antibiotic resistance gene \\
\hline HHuMIN D_00185 & cusR, copR, silR & 666 & 0745 & 07,665 & transcriptional regulatory protein & beta-lactam antibiotic resistance gene \\
\hline HHuMIN D_00391 & $m d l B, s m d B$ & 1794 & 1132 & 18,890 & $\begin{array}{l}\text { probable multidrug resistance } \mathrm{ABC} \\
\text { transporter ATP-binding/per- } \\
\text { mease protein YheH }\end{array}$ & multi antibiotic resistance gene \\
\hline HHuMIN D_00573 & aacC & 810 & 2746 & 00,662 & $\begin{array}{l}\text { aminoglycoside N(3)-acetyltrans- } \\
\text { ferase }\end{array}$ & $\begin{array}{l}\text { aminoglycoside antibiotic resistance } \\
\text { gene }\end{array}$ \\
\hline HHuMIN D_00588 & $\operatorname{mrcA}$ & 2379 & 0744 & 05,366 & peptidoglycan glycosyltransferase & beta-lactam antibiotic resistance gene \\
\hline HHuMIN D_00697 & $\mathrm{pbpB}$ & 2151 & 0768 & 08,724 & penicillin-binding protein 2B & beta-lactam antibiotic resistance gene \\
\hline HHuMIN D_00746 & sotB & 1383 & 0477 & 08,159 & lincomycin resistance protein LmrB & lincomycin antibiotic resistance gene \\
\hline HHuMIN D_00878 & $\operatorname{mrdA}$ & 2100 & 0768 & 05,515 & $\begin{array}{l}\text { serine-type D-Ala-D-Ala carboxy- } \\
\text { peptidase }\end{array}$ & beta-lactam antibiotic resistance gene \\
\hline HHuMIN D_01245 & gtrB, csbB & 933 & 0463 & 20,534 & $\begin{array}{l}\text { undecaprenyl-phosphate 4-deoxy- } \\
\text { 4-formamido-L-arabinose } \\
\text { transferase }\end{array}$ & polymyxin antibiotic resistance gene \\
\hline HHuMIN D_01314 & parE & 1959 & 0187 & 02,622 & DNA gyrase subunit & $\begin{array}{l}\text { aminocoumarin antibiotic resistance } \\
\text { gene }\end{array}$ \\
\hline HHuMIN D_01342 & $a b c A, b m r A$ & 996 & 1132 & 18,104 & xenobiotic-transporting ATPase & beta-lactam antibiotic resistance gene \\
\hline HHuMIN D_01640 & $d d p F$ & 678 & 1136 & 02,032 & $\begin{array}{l}\text { macrolide export ATP-binding/per- } \\
\text { mease protein MacB }\end{array}$ & macrolide antibiotic resistance gene \\
\hline HHuMIN D_01864 & pbp1b & 2829 & 0744 & 03,693 & penicillin-binding protein 1A & beta-lactam antibiotic resistance gene \\
\hline HHuMIN D_01995 & ABC.CD.P & 1869 & 0577 & 02,004 & $\begin{array}{l}\text { bacitracin export permease protein } \\
\text { BceB }\end{array}$ & bacitracin antibiotic resistance gene \\
\hline HHuMIN D_02034 & $\mathrm{cPoA}$ & 1044 & 0438 & 13,678 & $\begin{array}{l}\text { alpha-galactosylglucosyldiacylglyc- } \\
\text { erol synthase }\end{array}$ & beta-lactam antibiotic resistance gene \\
\hline HHuMIN D_02075 & metN & 690 & 1135 & 02,071 & $\begin{array}{l}\text { macrolide export ATP-binding/per- } \\
\text { mease protein MacB }\end{array}$ & macrolide antibiotic resistance gene \\
\hline
\end{tabular}


genes to intestinal pathogens [99]. Consequently, whole genome sequencing was used to determine whether the antibiotic-resistant genes of L. gasseri HHuMIN D could be transmitted through plasmids to other bacteria. No gene capable of delivering antibiotic resistance in the whole genome of $L$. gasseri HHuMIN D was found (data not shown). Since genes cannot be spread, antibiotic resistance to L. gasseri HHuMIN D is known to be inherent or normal. Several studies have documented that tolerance to aminoglycoside groups such as gentamicin, streptomycin, kanamycin and neomycin is suspected to be intrinsic to Lactobacillus spp. and is due to the absence of cytochrome-mediated electron transport that mediates drug absorption $[100,101]$.

\section{Conclusion}

Oral microorganisms can be classified into anaerobic microorganisms and aerobic microorganisms (including facultative anaerobes), based on their sensitivity to oxygen. Anaerobic microorganisms generally live in environments where oxygen penetration is minimal or nonexistent, such as gingival crevices or periodontal pockets, and induce diseases such as halitosis and periodontitis. Aerobic microorganisms mainly inhabit the buccal and palatal mucosae, especially the tongue, and some species form biofilms to settle oral microorganisms and provide an environment in which diseases such as tooth decay can be induced. Most Streptococcus spp. do not induce disease and are commonly found in the oral cavity. We sought to confirm the effects of the probiotics isolated in this study using 11 types of oral microorganisms that included general aerobic microorganisms, disease-inducing aerobic microorganisms, and disease-inducing anaerobic microorganisms. L. gasseri HHuMIN D culture supernatant inhibited halitosis producing anaerobic microorganisms by $88.8 \%$ and antimicrobial activity against deleterious oral bacteria was strong. Multiplication of L. gasseri HHuMIN D was impaired when co-cultured with other oral bacteria. $L$. gasseri HHuMIN D continuously released hydrogen peroxide after $12 \mathrm{~h}$ to $802 \mu \mathrm{mol} / \mathrm{L}$ and gradually decreased until 24 h. $P$. catoniae, and S. sanguinis were aggregated with L. gasseri HHuMIN D, and L. gasseri HHuMIN D decreased the manufacture of artificial dental plaque from $S$. mutans by $100 \%$. The KB cell adhesion ability of L. gasseri HHuMIN D was 4.41 cells per cell and the cell adhesion of $F$. nucleatum and $S$. mutans decreased dramatically in protection and displacement assays. These characteristics of L. gasseri HHuMIN D are thought to indirectly help inhibit harmful oral microorganisms. $L$. gasseri HHuMIN D showed direct inhibitory effects on the growth of oral pathogens. L. gasseri HHuMIN D does not produce biogenic amines and ammonia, hemolysis and mucin decomposition activity were not observed and antibiotic resistance testing and WGS analysis confirmed that there was no antibiotic resistance or genes associated with biogenic amines, platelet aggregation, virulence or antibiotic resistance. Three genes that express bacteriocin were identified. These assessments demonstrated compliance of the L. gasseri HHuMIN D with EFSA and FDA requirements and this study suggests that $L$. gasser $i$ HHuMIN D may be effective in inhibiting harmful oral bacteria and has potential for use as a natural probiotic, a functional food, or a food for wellbeing.

\section{Abbreviations \\ L. gasseri: Lactobacillus gasseri; F. nucleatum: Fusobacterium nucleatum; P. gingi- valis: Porphyromonas gingivalis; P. intermedia: Prevotella intermedia; P. catoniae: Porphyromonas catoniae; S. sobrinus: Streptococcus sobrinus; S. mitis: Streptococ- cus mitis; S. oralis: Streptococcus oralis; S. gordonii: Streptococcus gordonii; S. san- guinis: Streptococcus sanguinis; S. parasanguinis: Streptococcus parasanguinis; S. mutans: Streptococcus mutans; WGS: Whole genome sequencing; WHO: World Health Organization; GTase: Glucosyltransferase; VSCs: Volatile sulfur compounds; $\mathrm{H}_{2} \mathrm{~S}$ : Hydrogen sulfide; $\mathrm{CH}_{3} \mathrm{SH}$ : Methyl mercaptan; $\mathrm{CHX}$ : Chlorhex- idine; CPC: Cetylpyridinium chloride; FAO: Food and Agriculture Organiza- tion of the United Nations; TMB: Tetra methyl benzidine; DMSO: Dimethyl sulfoxide; MRS: De Man-Rogosa-Sharpe; PBS: Phosphate buffered saline; LBS: Lactobacillus Selection; BHI: Brain Heart Infusion; MSB: Mitis Salivarius Sucrose Bacitracin; FBS: Fetal bovine serum; MEM: Minimum critical medium; CFU: Colony-forming unit; CT: Cycle threshold; Trimethoprim: Trimethoprim-sul- famethoxazole; LSM-Cys: LAB susceptibility test medium with L-cysteine; MIC: Minimal inhibitory concentration; COG: Clusters of Orthologous Groups of proteins; KEGG: Kyoto Encyclopedia of Genes and Genomes; CGE: Center for Genomic Epidemiology; CARD: Comprehensive antibiotic resistance database; GTF: Glucosyl transferase; gtf: Glucosyltransferase; GBD: Glucan binding domain; BAs: Biogenic amines; CDSs: Coding sequences; MAT: Methionine adenosyltransferase.}

\section{Acknowledgements}

Not applicable.

\section{Authors' contributions}

Soyon Mann designed the experiment under the supervision of Geun Eog Ji, Myeong Soo Park and Seockmo Ku. Soyon Mann performed microbial experiments. Soyon Mann, Geun Eog Ji, Myeong Soo Park, Keum Taek Hwang and Seockmo Ku performed the literature research and analyzed data. Tony V. Johnston, Keum Taek Hwang and Seockmo Ku edited and revised the manuscript. Keum Taek Hwang and Seockmo Ku managed the entire process of Soyon Mann's publication as an academic advisor and co-advisor, respectively. Seockmo Ku and Tony V. Johnston participated this work based on a non-disclosure research agreement between Middle Tennessee State University and BIFIDO Co., Ltd. All authors discussed drafts and approved the final manuscript for publication.

\section{Funding}

This research was financially supported by the Gang-neung Science \& Industry Promotion Agency (GSIPA), Korea, under the "Regional development investment agreement pilot project". This work was also supported by a Faculty Research and Creative Activity Committee (FRCAC) grant (No. 221745) funded by Middle Tennessee State University in the U.S.

Availability of data and material

The datasets used and/or analysed during the current study are available from the corresponding author on reasonable request. 


\section{Declarations}

Ethics approval and consent to participate

Not applicable.

\section{Consent for publication}

Not applicable.

\section{Competing interests}

Soyon Mann, Tony V. Johnston, Keum Taek Hwang and Seockmo Ku declare no conflicts of interest. Geun Eog Ji and Myeong Soo Park hold BIFIDO Co., Ltd. stocks as a CEO and CTO, respectively.

\section{Author details}

${ }^{1}$ Department of Food and Nutrition, and Research Institute of Human Ecology, Seoul National University, Seoul 08826, Korea. ${ }^{2}$ Research Center, BIFIDO Co., Ltd, Hongcheon 25117, Korea. ${ }^{3}$ Fermentation Science Program, School of Agriculture, College of Basic and Applied Sciences, Middle Tennessee State University, Murfreesboro, TN 37132, USA.

\section{Received: 8 January 2021 Accepted: 9 March 2021}

Published online: 23 March 2021

\section{References}

1. CDC. Basics of oral health. https://www.cdc.gov/oralhealth/basics/ index.html. (2020). Accessed 01 Sep 2020.

2. Kassebaum N, Smith A, Bernabé E, Fleming T, Reynolds A, Vos T, Murray C, Marcenes W, Collaborators GOH. Global, regional, and national prevalence, incidence, and disability-adjusted life years for oral conditions for 195 countries, 1990-2015: a systematic analysis for the global burden of diseases, injuries, and risk factors. J Dent Res. 2017;96:380-7.

3. WHO. Oral health. https://www.who.int/health-topics/oral-health\#tab= tab_1. (2020). Accessed 01 Sep 2020.

4. Banas JA. Virulence properties of Streptococcus mutans. Front Biosci. 2004;9:1267-77.

5. Kuramitsu HK. The virulence properties of Streptococcus mutans. In: Gram-positive pathogens, 2nd Edn. American Society of Microbiology. 2006. Pp 340-346.

6. Tonzetich J. Direct gas chromatographic analysis of sulphur compounds in mouth air in man. Arch Oral Biol. 1971;16:587-97.

7. De Boever EH, Loesche WJ. Assessing the contribution of anaerobic microflora of the tongue to oral malodor. J Am Dent Assoc. 1995;126:1384-93.

8. Islam B, Khan SN, Khan AU. Dental caries: from infection to prevention. Med Sci Monit. 2007;13:96-203.

9. Daboor SM, Masood FSS, Al-Azab MS, Nori EE. A review on streptococcus mutans with its diseases dental caries, dental plaque and endocarditis. Indian J Microbiol Res. 2015;2:76-82.

10. Bustamante M, Oomah BD, Mosi-Roa Y, Rubilar M, Burgos-Díaz C. Probiotics as an adjunct therapy for the treatment of halitosis, dental caries and periodontitis. Probiotics Antimicrob Proteins. 2020;12:325-34.

11. Dobler D, Runkel F, Schmidts T. Effect of essential oils on oral halitosis treatment: a review. Eur J Oral Sci. 2020;128:476-86.

12. Fujita K, Matsumoto-Nakano M, Inagaki S, Ooshima T. Biological functions of glucan-binding protein B of Streptococcus mutans. Oral Microbiol Immunol. 2007;22:289-92.

13. Banavar Ravi S, Nirupad S, Chippagiri P, Pandurangappa R. Antibacterial effects of natural herbal extracts on streptococcus mutans: can they be potential additives in dentifrices. Int J Dent. 2017;2017:1-5.

14. Hur MH, Park J, Maddock-Jennings W, Kim DO, Lee MS. Reduction of mouth malodour and volatile sulphur compounds in intensive care patients using an essential oil mouthwash. Phytother Res. 2007:21:641-3.

15. Cho YJ. Isolation of 3-Galloylprocyanidin B3, a Glucosyltransferase Inhibitor from the Korean Green Tea Leaves. J Appl Biol Chem. 2000:43:273-6.

16. Hayes $C$. The effect of non-cariogenic sweeteners on the prevention of dental caries: a review of the evidence. J Dental Educ. 2001;65:1106-9.
17. Winkel EG, Roldan S, Van Winkelhoff AJ, Herrera D, Sanz M. Clinical effects of a new mouthrinse containing chlorhexidine, cetylpyridinium chloride and zinc-lactate on oral halitosis. A dual-center, double-blind placebo-controlled study. J Clin Periodontol. 2003;30:300-6.

18. Kim SE, Shim KM, Yoo KH, et al. The effect of Cetylpyridinium chloride on halitosis and periodontal disease-related parameters in dogs. Biotechnol Bioprocess Eng. 2008;13:252.

19. Oh JS. Isolation and clinical application of lactic acid bacteria inhibiting halitosis. Dissertation, University Chonnam. 2005.

20. Hatakka K, Ahola AJ, Yli-Knuuttila H, Richardson M, Poussa T, Meurman $\mathrm{JH}$, Korpela R. Probiotics reduce the prevalence of oral Candida in the elderly — a randomized controlled trial. J Dent Res. 2007;86:125-30.

21. Meurman JH, Stamatova I. Probiotics: contributions to oral health. Oral Dis. 2007;13:443-51.

22. Teanpaisan R, Piwat S, Dahlen G. Inhibitory effect of oral Lactobacillus against oral pathogens. Lett Appl Microbiol. 2011;53:452-9.

23. Sohn YW. Guidelines for standardization for quality of Lactobacillus products. National Institute of Food and Drug Safety Evaluation; 2016.

24. FAO, WHO. Guidelines for the evaluation of probiotics in food. Food and Agriculture Organization of the United Nations \& World Health Organization; 2002.

25. Eschenbach DA, Davick PR, Williams BL, Klebanoff SJ, Young-Smith K, Critchlow C, Holmes KK. Prevalence of hydrogen peroxide-producing Lactobacillus species in normal women and women with bacterial vaginosis. J Clin Microbiol. 1989;27:251-6.

26. Spencer JFT, Spencer ALRD. Public health microbiology: Methods and protocols (methods in molecular biology). New Jersey: Humana Press; 2004.

27. Jung SS, Choi Jl, Joo WH, Suh HH, Na AS, Cho YK, Moon JY, Ha KC, Paik $\mathrm{DH}$, Kang DO. Characterization and purification of the bacteriocin produced by Bacillus licheniformis isolated from soybean sauce. J Life Sci. 2009;19:994-1002.

28. Handley PS, Harty DW, Wyatt JE, Brown CR, Doran JP, Gibbs AC. A comparison of the adhesion, coaggregation and cell-surface hydrophobicity properties of fibrillar and fimbriate strains of Streptococcus salivarius. Microbiology. 1987;133:3207-17.

29. Yu SH, Kwak SH, Nguyen TTH, Seo YS, Song C, Mok IK, Kim D. Decrease of insoluble glucan formation in Streptococcus mutans by co-cultivation with Enterococcus faecium T7 and glucanase addition. Biotechnol Lett. 2018:40:375-81.

30. Ren D, Li C, Qin Y, Yin R, Li X, Tian M, Du S, Guo H, Liu C, Zhu N. Inhibition of Staphylococcus aureus adherence to Caco-2 cells by lactobacilli and cell surface properties that influence attachment. Anaerobe. 2012;18:508-15.

31. Ringuet S, Sassano L, Johnson ZI. A suite of microplate reader-based colorimetric methods to quantify ammonium, nitrate, orthophosphate and silicate concentrations for aquatic nutrient monitoring. J Environ Monit. 2011;13:370-6.

32. Kim M, Ku S, Kim S, Lee H, Jin H, Kang S, Li R, Johnston T, Park M, Ji G. Safety Evaluations of Bifidobacterium bifidum BGN4 and Bifidobacterium longum BORI. Int J Mol Sci. 2018;19:1422.

33. Borriello S, Hammes W, Holzapfel W, Marteau P, Schrezenmeir J, Vaara M, Valtonen $\mathrm{V}$. Safety of probiotics that contain lactobacilli or bifidobacteria. Clin Infect Dis. 2003;36:775-80.

34. Ammor MS, Flórez AB, Mayo B. Antibiotic resistance in non-enterococcal lactic acid bacteria and bifidobacteria. Food Microbiol. 2007:24:559-70.

35. Kanehisa M, Goto S, Kawashima S, Okuno Y, Hattori M. The KEGG resource for deciphering the genome. Nucleic Acids Res. 2004;32:D277-80

36. Overbeek R, Olson R, Pusch GD, Olsen GJ, Davis JJ, Disz T, Edwards RA, Gerdes S, Parrello B, Shukla M. The SEED and the Rapid Annotation of microbial genomes using Subsystems Technology (RAST). Nucleic Acids Res. 2014:42:D206-14.

37. Tatusov RL, Fedorova ND, Jackson JD, Jacobs AR, Kiryutin B, Koonin EV, Krylov DM, Mazumder R, Mekhedov SL, Nikolskaya AN. The COG database: an updated version includes eukaryotes. BMC Bioinform. 2003:4:41.

38. Watanabe K, Harayama S. SWISS-PROT: the curated protein sequence database on Internet. Tanpakushitsu Kakusan Koso Protein, Nucleic Acid Enzyme. 2001;46:80. 
39. Wannun P, Piwat S, Teanpaisan R. Purification and characterization of bacteriocin produced by oral Lactobacillus paracasei SD1. Anaerobe. 2014;27:17-21.

40. Samot J, Badet C. Antibacterial activity of probiotic candidates for oral health. Anaerobe. 2013;19:34-8.

41. Burton J, Chilcott C, Tagg J. The rationale and potential for the reduction of oral malodour using Streptococcus salivarius probiotics. Oral Dis. 2005;11:29-31.

42. Fuochi V, LiVolti G, Furneri PM. Probiotic properties of Lactobacillus fermentum strains isolated from human oral samples and description of their antibacterial activity. Curr Pharm Biotechnol. 2017;18:138-49.

43. Caglar E, Kargul B, Tanboga I. Bacteriotherapy and probiotics' role on oral health. Oral Dis. 2005;11:131-7.

44. Teanpaisan T, Dahlen G. Use of polymerase chain reaction techniques and sodium dodecyl sulfate-polyacrylamide gel electrophoresis for differentiation of oral Lactobacillus species. Oral Microbiol Immunol. 2006;21:79-83.

45. Teughels W, Van Essche M, Sliepen I, Quirynen M. Probiotics and oral healthcare. Periodontol. 2000;2008(48):111-47.

46. Mastromarino $P$, Vitali $B$, Mosca L. Bacterial vaginosis: a review on clinical trials with probiotics. New Microbiol. 2013;36:229-38.

47. Olivares M, Díaz-Ropero MP, Gómez N, Lara-Villoslada F, Sierra S, Maldonado JA, Martín R, López-Huertas E, Rodríguez JM, Xaus J. Oral administration of two probiotic strains, Lactobacillus gasseri CECT5714 and Lactobacillus coryniformis CECT5711, enhances the intestinal function of healthy adults. Int J Food Microbiol. 2006;107:104-11.

48. Chen LJ, Tsai HT, Chen WJ, Hsieh CY, Wang PC, Chen CS, Wang L, Yang CC. In vitro antagonistic growth effects of Lactobacillus fermentum and Lactobacillus salivarius and their fermentative broth on periodontal pathogens. Braz J Microbiol. 2012;43:1376-84.

49. Gao Z, Daliri EBM, Wang J, Liu D, Chen S, Ye X, Ding T. Inhibitory effect of lactic acid bacteria on foodborne pathogens: a review. J Food Prot. 2019;82:441-53.

50. Otero MC, Nader-Macías ME. Inhibition of Staphylococcus aureus by $\mathrm{H}_{2} \mathrm{O}_{2}$-producing Lactobacillus gasseri isolated from the vaginal tract of cattle. Anim Reprod Sci. 2006:96:35-46.

51. Shokri D, Khorasgani MR, Mohkam M, Fatemi SM, Ghasemi Y, TaheriKafrani A. The inhibition effect of lactobacilli against growth and biofilm formation of Pseudomonas aeruginosa. Probiotics Antimicrob Proteins. 2018;10:34-42.

52. Sabir F, Beyatli Y, Cokmus C, Onal-Darilmaz D. Assessment of potential probiotic properties of Lactobacillus spp., Lactococcus spp., and Pediococcus spp. strains isolated from kefir. J Food Sci. 2010;75:568-73.

53. Ito A, Sato Y, Kudo S, Sato S, Nakajima H, Toba T. The screening of hydrogen peroxide-producing lactic acid bacteria and their application to inactivating psychrotrophic food-borne pathogens. Curr Microbiol. 2003:47:0231-6.

54. Pridmore RD, Pittet A-C, Praplan F, Cavadini C. Hydrogen peroxide production by Lactobacillus johnsonii NCC 533 and its role in antiSalmonella activity. FEMS Microbiol Lett. 2008;283:210-5.

55. Van der Hoeven J, Camp P. Mixed continuous cultures of Streptococcus mutans with Streptococcus sanguis or with Streptococcus oralis as a model to study the ecological effects of the lactoperoxidase system. Caries Res. 1993;27:26-30.

56. Chatterjee A, Bhattacharya $\mathrm{H}$, Kandwal A. Probiotics in periodontal health and disease. J Indian Soc Periodontol. 2011;15:23.

57. Cleveland J, Montville TJ, Nes IF, Chikindas ML. Bacteriocins: safe, natural antimicrobials for food preservation. Int J Food Microbiol. 2001;71:1-20.

58. Subramanian S, Smith DL. Bacteriocins from the rhizosphere microbiome-from an agriculture perspective. Front Plant Sci. 2015;6:909.

59. Yang SC, Lin CH, Sung CT, Fang JY. Antibacterial activities of bacteriocins: application in foods and pharmaceuticals. Front Microbiol. 2014,5:241.

60. Wannun P, Piwat S, Teanpaisan R. Purification, characterization, and optimum conditions of fermencin SD11, a bacteriocin produced by human orally Lactobacillus fermentum SD11. Appl Biochem Biotechnol. 2016;179:572-82

61. Twetman L, Larsen U, Fiehn N-E, Stecksén-Blicks C, Twetman S. Coaggregation between probiotic bacteria and caries-associated strains: an in vitro study. Acta Odontol Scand. 2009;67:284-8.
62. Sakamoto M, Umeda M, Benno Y. Molecular analysis of human oral microbiota. J Periodontal Res. 2005:40:277-85.

63. Kolenbrander PE, Andersen RN, Blehert DS, Egland PG, Foster JS, Palmer RJ. Communication among oral bacteria. Microbiol Mol Biol Rev. 2002;66:486-505

64. Comelli EM, Guggenheim B, Stingele F, Neeser JR. Selection of dairy bacterial strains as probiotics for oral health. Eur J Oral Sci. 2002;110:218-24.

65. Kang MS, Na HS, Oh JS. Coaggregation ability of Weissella cibaria isolates with Fusobacterium nucleatum and their adhesiveness to epithelial cells. FEMS Microbiol Lett. 2005;253:323-9.

66. Koo H, Rosalen PL, Cury JA, Park YK, Bowen WH. Effects of compounds found in propolis on Streptococcus mutans growth and on glucosyltransferase activity. Antimicrob Agents Chemother. 2002:46:1302-9.

67. Nishimura J, Saito T, Yoneyama H, Bai LL, Okumura K, Isogai E. Biofilm formation by Streptococcus mutans and related bacteria. Adv Microbiol. 2012;2:208.

68. Chung J, Yim SY, Oh JS. Effect of Lactococcus lactis 1370 on the formation of artificial plaque. J Korean Soc Microbiol. 2000;35:77-85.

69. Koh CM, Kim SK. Correlative reationship between proteinase, phospholipase activity and adherence to buccal epithelial cells of experimental strains of Candida albicans. J Korean Soc Microbiol. 1987;22:403-11.

70. Han TW, Shi W, Huang GTJ, Haake SK, Park NH, Kuramitsu H, Genco RJ. Interactions between periodontal bacteria and human oral epithelial cells: Fusobacterium nucleatum adheres to and invades epithelial cells. Infect Immun. 2000;68:3140-6.

71. García-Ruiz A, de Llano DG, Esteban-Fernández A, Requena T, Bartolomé B, Moreno-Arribas MV. Assessment of probiotic properties in lactic acid bacteria isolated from wine. Food Microbiol. 2014:44:220-5.

72. Igai K, Itakura M, Nishijima S, Tsurumaru H, Suda W, Tsutaya T, Tomitsuka E, Tadokoro K, Baba J, Odani S. Nitrogen fixation and nifH diversity in human gut microbiota. Sci Rep. 2016;6:31942.

73. Vince AJ, Burridge SM. Ammonia production by intestinal bacteria: the effects of lactose, lactulose and glucose. J Med Microbiol. 1980;13:177-91.

74. Smith EA, Macfarlane GT. Formation of phenolic and indolic compounds by anaerobic bacteria in the human large intestine. Microb Ecol. 1997;33:180-8.

75. Önal A. A review: Current analytical methods for the determination of biogenic amines in foods. Food Chem. 2007;103:1475-86.

76. Ku S. Finding and producing probiotic glycosylases for the biocatalysis of ginsenosides: a mini review. Molecules. 2016;21:645.

77. Goldstein EJ, Tyrrell KL. Citron DM Lactobacillus species: taxonomic complexity and controversial susceptibilities. Clin Infect Dis. 2015;60:S98-107.

78. Gómez NC, Ramiro JM, Quecan BX, de Melo Franco BD. Use of potential probiotic lactic acid bacteria ( $\mathrm{LAB}$ ) biofilms for the control of Listeria monocytogenes, Salmonella typhimurium, and Escherichia coli O157: H7 biofilms formation. Front Microbiol. 2016;7:863.

79. Levy GN, Aminoff D. Purification and properties of alpha-Nacetylgalactosaminidase from Clostridium perfringens. J Biol Chem. 1980;255:11737-42

80. Prizont R. Degradation of intestinal glycoproteins by pathogenic Shigella flexneri. Infect Immun. 1982;36:615-20.

81. Slomiany B, Murty V, Piotrowski J, Liau Y, Sundaram P, Slomiany A. Glycosulfatase activity of Helicobacter pylori toward gastric mucin. Biochem Biophys Res Commun. 1992;183:506-13.

82. Tailford LE, Crost EH, Kavanaugh D, Juge N. Mucin glycan foraging in the human gut microbiome. Front Genetics. 2015;6:81.

83. De Groote MA, Frank DN, Dowell E, Glode MP, Pace NR. Lactobacillus rhamnosus GG bacteremia associated with probiotic use in a child with short gut syndrome. Pediatr Infect Dis J. 2005;24:278-80.

84. Liong MT. Safety of probiotics: translocation and infection. Nutr Rev. 2008;66:192-202.

85. Ruas-Madiedo P, Gueimonde M, Fernández-García M, Clara G, Margolles A. Mucin degradation by Bifidobacterium strains isolated from the human intestinal microbiota. Appl Environ Microbiol. 2008;74:1936-40.

86. Additives EPo, Feed PoSuiA. Guidance on the assessment of bacterial susceptibility to antimicrobials of human and veterinary importance. EFSA;2012;10:2740. 
87. Cárdenas N, Laiño JE, Delgado S, Jiménez E, Del Valle MJ, De Giori GS, Sesma F, Mayo B, Fernández L, LeBlanc JG. Relationships between the genome and some phenotypical properties of Lactobacillus fermentum CECT 5716, a probiotic strain isolated from human milk. Applied Microbiol Biotechnol. 2015;99:4343-53.

88. Mayer LW. Use of plasmid profiles in epidemiologic surveillance of disease outbreaks and in tracing the transmission of antibiotic resistance. Clin Microbiol Rev. 1988;1:228-43.

89. Piddock LJ. Multidrug-resistance efflux pumps? not just for resistance. Nat Rev Microbiol. 2006;4:629-36.

90. Tagg JR, Dajani AS, Wannamaker LW. Bacteriocins of gram-positive bacteria. Bacteriol Rev. 1976:40:722.

91. Gänzle MG, Weber S, Hammes WP. Effect of ecological factors on the inhibitory spectrum and activity of bacteriocins. Int J Food Microbiol. 1999;46:207-17

92. Klaenhammer TR. Bacteriocins of lactic acid bacteria. Biochimie. 1988;70:337-49.

93. Fujisawa T, Benno Y, Yaeshima T, Mitsuoka T. Taxonomic study of the Lactobacillus acidophilus group, with recognition of Lactobacillus gallinarum sp. nov. and Lactobacillus johnsonii sp. nov. and synonymy of Lactobacillus acidophilus group A3 (Johnson et al. 1980) with the type strain of Lactobacillus amylovorus (Nakamura 1981). Int J Syst Evol Microbiol. 1992;42:487-91.

94. Itoh T, Fujimoto Y, Kawai Y, Toba T, Saito T. Inhibition of food-borne pathogenic bacteria by bacteriocins from Lactobacillus gasseri. Lett Appl Microbiol. 1995;21:137-41.

95. Kawai Y, Saito T, Kitazawa H, Itoh T. Gassericin A; an uncommon cyclic bacteriocin produced by Lactobacillus gasseri LA39 linked at N-and C-terminal ends. Biosci Biotechnol Biochem. 1998;62:2438-40.

96. Zhu W, Liu W, Wu D. Isolation and characterization of a new bacteriocin from Lactobacillus gasseri KT7. J Appl Microbiol. 2000;88:877-86.

97. Kawai Y, Saitoh B, Takahashi O, Kitazawa H, Saito T, Nakajima H, Itoh T. Primary amino acid and DNA sequences of gassericin $\mathrm{T}$, a lactacin
F-family bacteriocin produced by Lactobacillus gasseri SBT2055. Biosci Biotechnol Biochem. 2000;64:2201-8.

98. Joerger MC, Klaenhammer TR. Characterization and purification of helveticin $\mathrm{J}$ and evidence for a chromosomally determined bacteriocin produced by Lactobacillus helveticus 481. J Bacteriol. 1986;167:439-46.

99. McDermott PF, Zhao S, Wagner DD, Simjee S, Walker RD, White DG. The food safety perspective of antibiotic resistance. Anim Biotechnol. 2002;13:71-84

100. Danielsen M, Wind A. Susceptibility of Lactobacillus spp. to antimicrobial agents. Int J Food Microbiol. 2003;82:1-11.

101. Monteagudo-Mera A, Rodríguez-Aparicio L, Rúa J, Martínez-Blanco H, Navasa N, García-Armesto MR, Ferrero MÁ. In vitro evaluation of physiological probiotic properties of different lactic acid bacteria strains of dairy and human origin. J Funct Foods. 2012;4:531-41.

102. Ivanova P, Peykov S, Dimitrova A, Dimov S. Molecular typing by genusspecific PCR and RAPD profiling of diverse Lactobacillus delbrueckii strains isolated from cow, sheep and buffalo yoghurts. Biotechnol Biotechnol Equip. 2008;22:748-53

103. Cogulu D, Uzel A, Oncag O, Eronat C. PCR-based identification of selected pathogens associated with endodontic infections in deciduous and permanent teeth. Oral Surg Oral Med Oral Pathol Oral Radiol Endodontol. 2008;106:443-9.

104. Lee SJ, Lee SH, Choi BK, Kim JW, Kim YJ, Kim CC. The influence of Lactobacillus rhamnosus GG on the binding ability of Streptococcus mutans. J Korean Acad Pedtatr Dent. 2011;38:155-60.

\section{Publisher's Note}

Springer Nature remains neutral with regard to jurisdictional claims in published maps and institutional affiliations.
Ready to submit your research? Choose BMC and benefit from:

- fast, convenient online submission

- thorough peer review by experienced researchers in your field

- rapid publication on acceptance

- support for research data, including large and complex data types

- gold Open Access which fosters wider collaboration and increased citations

- maximum visibility for your research: over 100M website views per year

At BMC, research is always in progress.

Learn more biomedcentral.com/submissions 